\title{
Simulation of marine boundary layer characteristics using a 1-D PBL model over the Bay of Bengal during BOBMEX-99
}

\author{
N V Sam, U C Mohanty* and A N V Satyanarayana \\ Centre for Atmospheric Sciences, Indian Institute of Technology, Hauz Khas, New Delhi 110 016, India. \\ *e-mail: mohanty@cas.iitd.ernet.in
}

The characteristic features of the marine boundary layer (MBL) over the Bay of Bengal during the southwest monsoon and the factors influencing it are investigated. The Bay of Bengal and Monsoon Experiment (BOBMEX) carried out during July - August 1999 is the first observational experiment under the Indian Climate Research Programme (ICRP). A very high-resolution data in the vertical was obtained during this experiment, which was used to study the MBL characteristics off the east coast of India in the north and south Bay of Bengal. Spells of active and suppressed convection over the Bay were observed, of which, three representative convective episodes were considered for the study. For this purpose a one-dimensional multi-level PBL model with a TKE- $\varepsilon$ closure scheme was used. The soundings, viz., the vertical profiles of temperature, humidity, zonal and meridional component of wind, obtained onboard ORV Sagar Kanya and from coastal stations along the east coast are used for the study. The temporal evolution of turbulent kinetic energy, marine boundary layer height (MBLH), sensible and latent heat fluxes and drag coefficient of momentum are simulated for different epochs of monsoon and monsoon depressions during BOBMEX-99.The model also generates the vertical profiles of potential temperature, specific humidity, zonal and meridional wind. These simulated values compared reasonably well with the observations available from BOBMEX.

\section{Introduction}

One of the primary objectives of the Bay of Bengal and Monsoon Experiment (BOBMEX) was to study the convective systems over the Bay of Bengal. The mechanism of its genesis and propagation as a synoptic scale system over the Bay of Bengal is also an important part of the experiment. BOBMEX, an observational programme under the Indian Climate Research Programme (ICRP) was aimed at measuring important variables of the atmosphere, ocean and from their interface, to have a greater depth of insight into some of the processes that govern organized convective activity over the Bay of Bengal and its variability (Bhat et al 2001, 2002). Understanding the nature of the feedback between the atmospheric convection and surface conditions of the Bay is important for understanding the variability of convection over the Bay. TOGA COARE (Tropical Ocean Global Atmosphere Coupled Ocean Atmosphere Response Experiment), which was aimed to describe the coupling of the west Pacific warm pool to the atmosphere (Webster and Lukas 1992), gave an insight into the atmosphere-ocean coupling on timescales that is intra-seasonal (Godfrey and Lindstorm 1989; Shinoda et al 1998). The movement of the Tropical Convergence Zone (TCZ) over the oceans during the active and weak phases of the monsoon may depend on the feedback due to the mid-tropospheric warming by clouds in the same region. This movement is supposed to be characterized by the intensified circulation by other TCZs in the vicinity (Sikka and Gadgil 1980). It is

Keywords. Sensible and latent heat fluxes; marine boundary layer; turbulent kinetic energy. 
well established that Convective Available Potential Energy (CAPE) is high before the growth of a deep convection (William and Reno 1993) and as it starts precipitating, winds and downdrafts lower the energy of the air near the surface, while deep cloud activity makes the upper troposphere warmer, making the atmosphere stable and hence substantially reducing CAPE (Emmanuel 1994).

The surface fluxes of sensible and latent heat provide the energy for driving the atmospheric disturbances and the Marine Boundary Layer (MBL), plays an essential role in regulating the transport of energy and moisture upward into the atmosphere from the surface. The energy supplied to the atmosphere is mostly trapped in the MBL, except in regions of deep convection. Therefore, it is important to understand the various characteristics of the MBL namely the MBL height, the thermal stratification of the atmosphere, etc., during the growth of a deep convective activity. Studies carried out in the past over the Pacific Ocean show that MBL plays a key role in the growth and sustenance of the tropical disturbances. In regions of deep convection, there is an upward transport of moisture rich air in the MBL into the cumulonimbus clouds and downward transport of drier air to the surface. This interaction between convection and the boundary layer processes can lead to intraseasonal variability of convection (Neelin et al 1987; Yano and Emmanuel 1991). It is also a well known fact that the majority of the disturbances that are responsible for the monsoon rainfall over the Indian region are generated over the warm ocean around the subcontinent, the maximum numbers observed over the Bay of Bengal. The frequency of the genesis of these disturbances and the role of MBL in its growth and modifications need to be understood to link it with the variability of the monsoon.

The objectives of this paper are to analyse the MBL characteristics, while accounting for viz., the vertical stability of the atmosphere and the structure of the atmospheric boundary layer and the surface fluxes over the Bay of Bengal during the final phase of BOBMEX (1999), during three different synoptic situations. Some of the important questions that have been addressed are:

- What is the structure of the boundary layer over the Bay of Bengal during the southwest monsoon period?

- What are the local factors that influence the variability in the boundary layer height?

The analysis further provides insights into the temporal evolution of the turbulent kinetic energy (TKE) that is the contribution due to shear and buoyancy with respect to high wind speed and convectively active state of the atmosphere respectively. One of the secondary objectives of the study is to validate the model using observations obtained over the Bay of Bengal onboard ORV Sagar Kanya, and to see the variations in the surface fluxes (sensible and latent heat) during the three varied synoptic conditions.

\section{Data}

The upper air sounding and surface observations were obtained onboard ORV Sagar Kanya (\#SK147b) during 11th-13th August 1999. The sounding data comprised high-resolution (averaged to $50 \mathrm{~m}$, vertical resolution) profiles using a GPS sonde system. This contained winds and thermodynamic variables from surface ('10 m) to about $15 \mathrm{~km}$. As our objective is to study the MBL characteristics, we focus on the first $2 \mathrm{~km}$ in the vertical. Additional data comprised surface meteorological variables including the sea surface temperature (SST). Surface data corresponding to radiosonde launches are used in the model as described subsequently. The ship track of ORV Sagar Kanya (\#SK147B) is given in figure 1. The ship took its course from Paradip on 11th August to reach Chennai on 31st August 1999. Three cases are marked based on the surface synoptic observations taken onboard ORV Sagar Kanya, Indian Daily Weather Report (IDWR), NCMRWF analysis, satellite pictures and Weather in India (monsoon season, June-September, 2000) compiled by Thapilyal et al 1999.

\section{Synoptic conditions}

Satellite imagery (figure 2a) from INSAT (courtesy IMD) at 0600 UTC of 12th August 1999, indicates that cloudiness has increased over northeast and east central Bay. Scattered to moderate intense convection, north of $14^{\circ} \mathrm{N}$ and east of $90^{\circ} \mathrm{E}$, in association with a trough that is developing along the Arakan Coast is seen. This is indicative of the revival of monsoon in the next two days. Over the period from 13th-15th August 1999, the convection gets intensified over northeast Bay, north part of the Andaman Sea and over the Arakan Coast and subsequent precipitation is also observed. On 15 th an average of $43 \mathrm{~mm}\left(17.5^{\circ} \mathrm{N}, 89.0^{\circ} \mathrm{E}\right)$ rain is observed. There is also a pressure drop of approximately $2 \mathrm{mb}$ from the past two days and observed wind speed is of the order of $13.5 \mathrm{~ms}^{-1}$. Therefore the period (13th-15th August, 1999) was chosen as the active convection period for this study, hereafter called as Case $1\left(17.54^{\circ} \mathrm{N}, 89.02^{\circ} \mathrm{E}\right)$.

During 22nd-24th August, 1999, when ORV Sagar Kanya is cruising around $17.59^{\circ} \mathrm{N}$ and $88.84^{\circ} \mathrm{E}$ (figure $2 \mathrm{~b}$ ), two significant cloud masses 


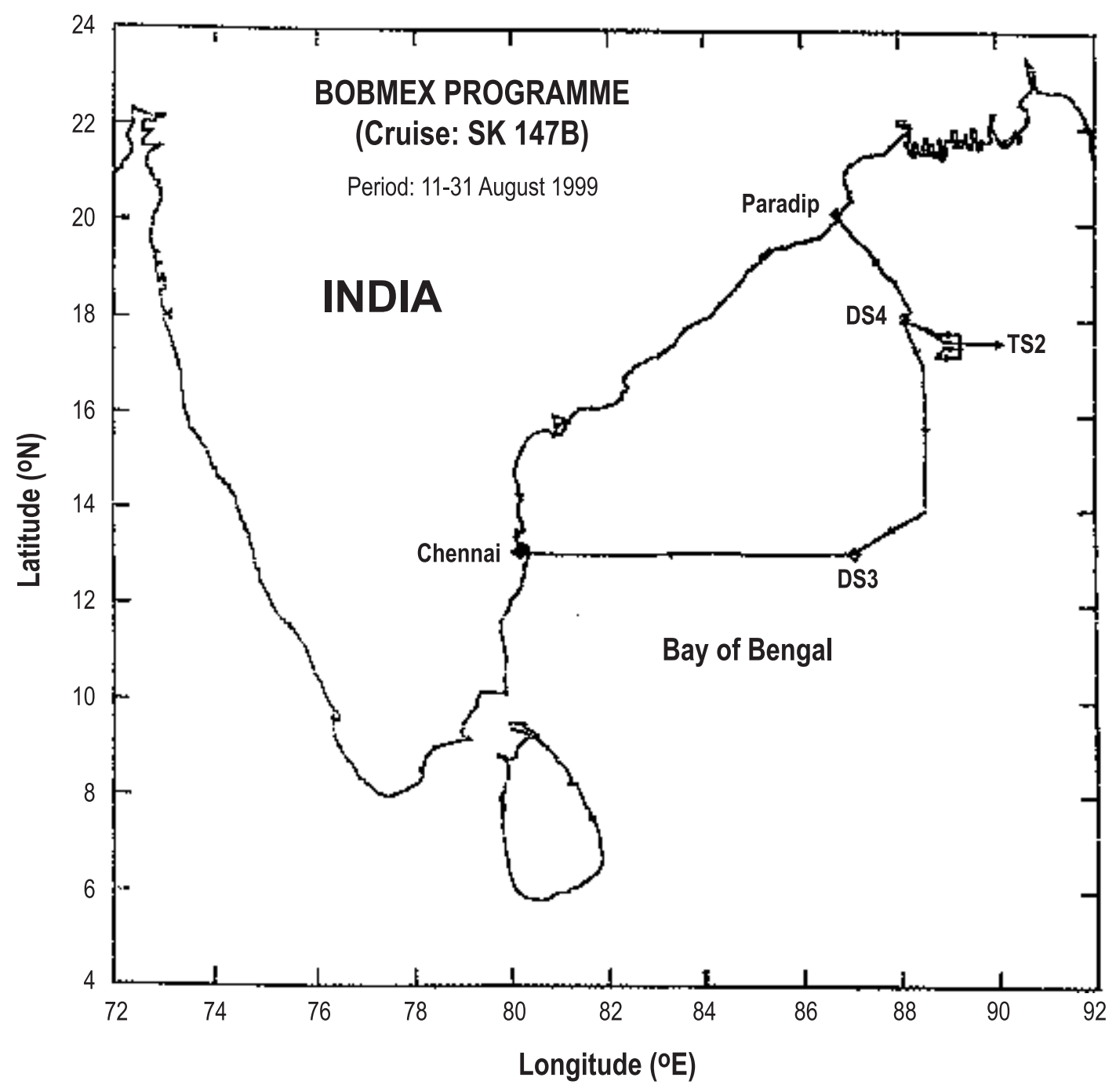

Figure 1. Cruise track of ORV Sagar Kanya (SK - 147 B).

are noticed viz., one covering the Maldives area between equator to $6.5^{\circ} \mathrm{N}$ and longitude $70-85^{\circ} \mathrm{E}$ and the other over south Andaman Sea and adjoining southeast Bay of Bengal between latitude $5-11^{\circ} \mathrm{N}$ and longitude $90-100^{\circ} \mathrm{E}$. During this period Sagar Kanya cruised through a relatively cloud free zone and the observed wind speed are of the order of $4 \mathrm{~ms}^{-1}$. This period $(22 \mathrm{nd}-24 \mathrm{th}$ August, 1999) is therefore termed as the suppressed convection period of the study, hereafter called as Case 2.

On 25th August 1999, a low-pressure area over west central Bay off north coastal Andhra Pradesh is noticed. The associated circulation extends up to mid troposphere tilting southward with height. Satellite imagery at 0600 UTC (figure 2c) indicates deep convection in the west central and southwest Bay west of $85^{\circ} \mathrm{E}$. During this period from 24th26th August $1999\left(15.5^{\circ} \mathrm{N}, 88.0^{\circ} \mathrm{E}\right)$, a growth in the convective activity is noticed over the 48 hours. From 23rd August 1999 (09 UTC), a change in the regime takes place, wherein, it is seen that the westerlies are tending to become easterlies, indicating the approach of a disturbance. Therefore this period is referred to as the transition period for this study, hereafter called as Case 3. Observed profiles of zonal and meridional winds, for the whole period of study are plotted (all the three cases) together in figure 3. Low wind speeds are observed at higher levels $(\sim 900 \mathrm{~m})$ for convectively suppressed conditions while winds are of the order of $20 \mathrm{~ms}^{-1}$ for convectively active conditions. There is a clear transition in the wind speed from low to high in Case 3 (figure 3 e and $\mathrm{f}$ ).

\section{Initial conditions and numerical experiments}

In this study a one-dimensional primitive equation, TKE- $\varepsilon$ closure based planetary boundary layer (PBL) model is used. The model has 40 levels in 
a)

13-08-1999

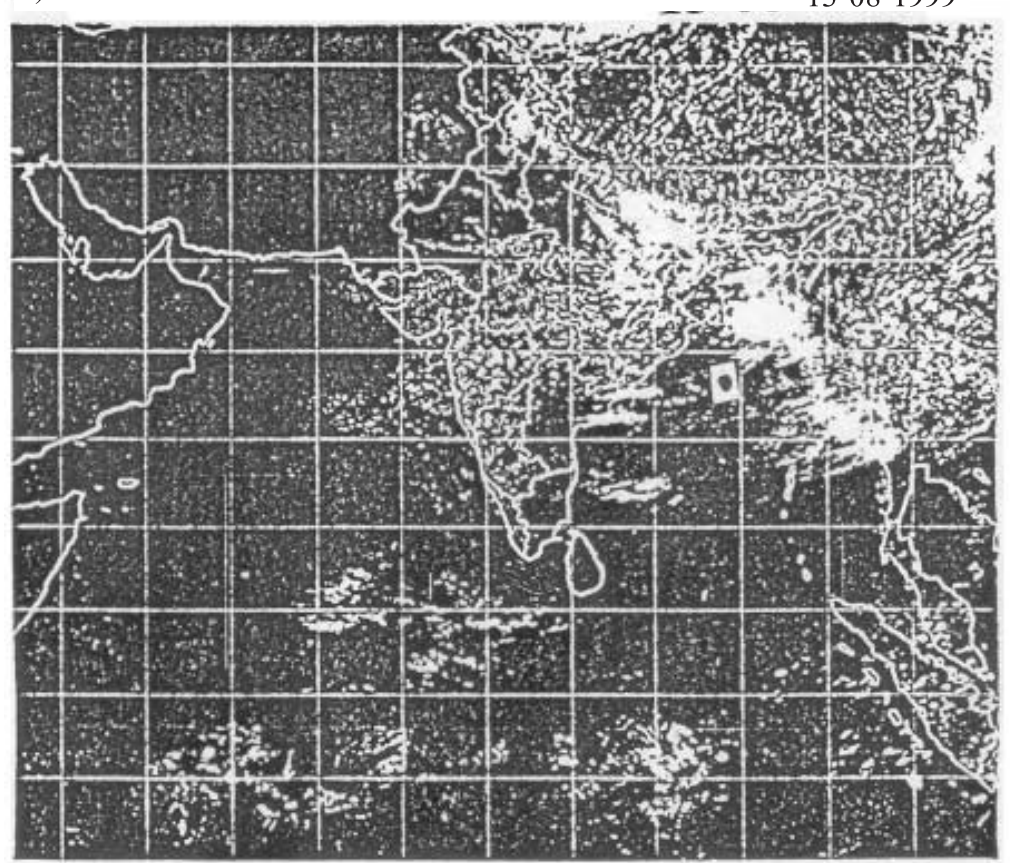

Approx. Ship Location

$\left(17.54^{\circ} \mathrm{N}, 89.02^{\circ} \mathrm{E}\right)$

b)

22-08-1999

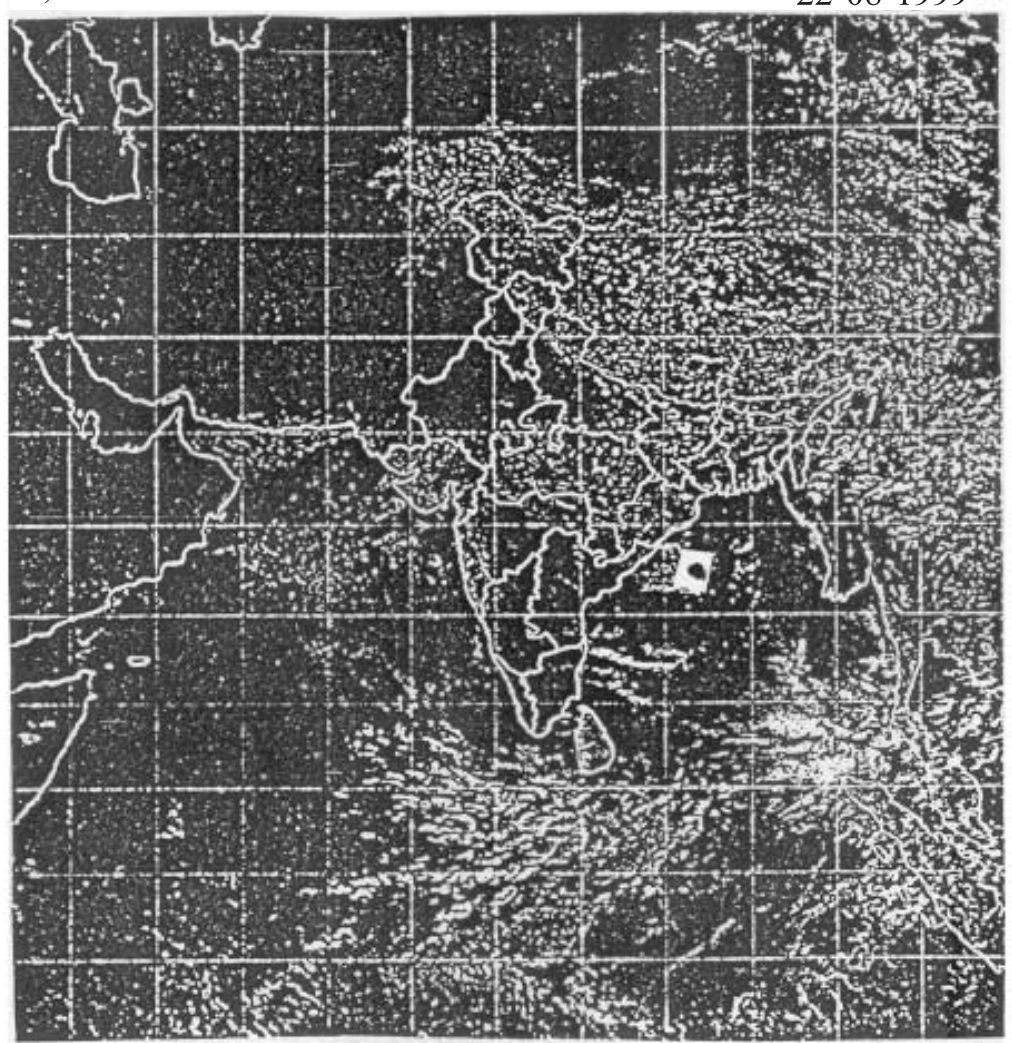

Approx. Ship Location

$\left(17.59^{\circ} \mathrm{N}, 88.84^{\circ} \mathrm{E}\right)$

Figure 2. Satellite imagery at 0600 UTC (from INSAT) representing (a) active convection period, (b) suppressed convection period. 
c)

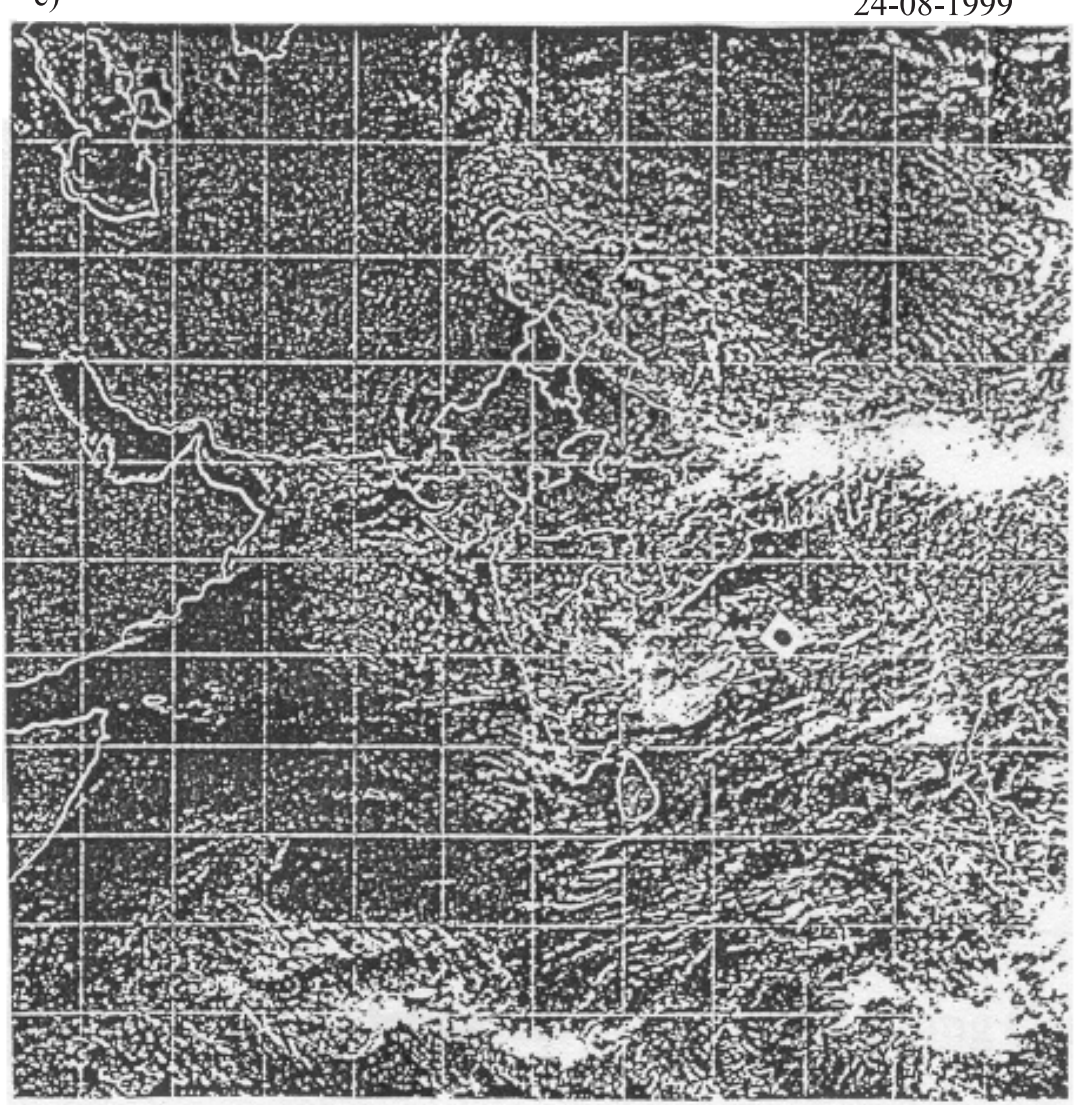

Approx. Ship Location

$\left(15.50^{\circ} \mathrm{N}, 88.00^{\circ} \mathrm{E}\right)$

Figure 2. Satellite imagery at 0600 UTC (from INSAT) representing (c) transition period.

the vertical with an average layer thickness of $50 \mathrm{~m}$ from the surface to $2000 \mathrm{~m}$. There are prognostic equations for winds, temperature, humidity, liquid water content and pressure. The geostrophic balance is achieved through pressure gradient and thermal wind equation, while setting the model initial conditions and its subsequent integration (Holton 1992). As mentioned, the model adopts TKE- $\varepsilon$ mixed layer parameterisation scheme while the surface layer similarity approach is used for the constant flux layer close to the surface (ocean in this study). Lykossov and Platov (1992) and Satyanarayana et al (1999 and 2000) give details of the model. A brief overview is also presented in table 1.

The data comprising vertical profiles of winds, temperature and humidity at different levels are utilized for the model initial and boundary conditions. The data sets consisting of vertical profiles of the above-cited parameters are processed to pick data at every $50 \mathrm{~m}$ in vertical from sea level to the top of the model domain using a linear inter- polation technique. The maximum height of the turbulent boundary layer (PBL top) is chosen as the upper boundary. The MBL height is taken as the height where turbulence ceases to exist. The wind speed, the potential temperature and moisture attain the observed values at the top of the boundary layer. The TKE and energy dissipation is assumed to vanish at that height. Analysis of the observed boundary layer heights indicated a maximum of $1400 \mathrm{~m}$. Hence the top of the model domain is kept at $2000 \mathrm{~m}$. To study the MBL characteristics, these data sets served as an input to the 1-D PBL multilevel model as well as time varying lateral boundary conditions. The model generated the vertical profiles of zonal and meridional winds, potential temperature and specific humidity, that are compared with the observed profiles for validation. In the 1-D PBL model, the PBL is separated into two domains: the near-surface constant-flux layer $(z \leq h)$ and the interfacial layer $(h<z \leq H)$. It is assumed that $h$ and $H$ do not vary in time. In order to calculate vertical turbulent fluxes of 


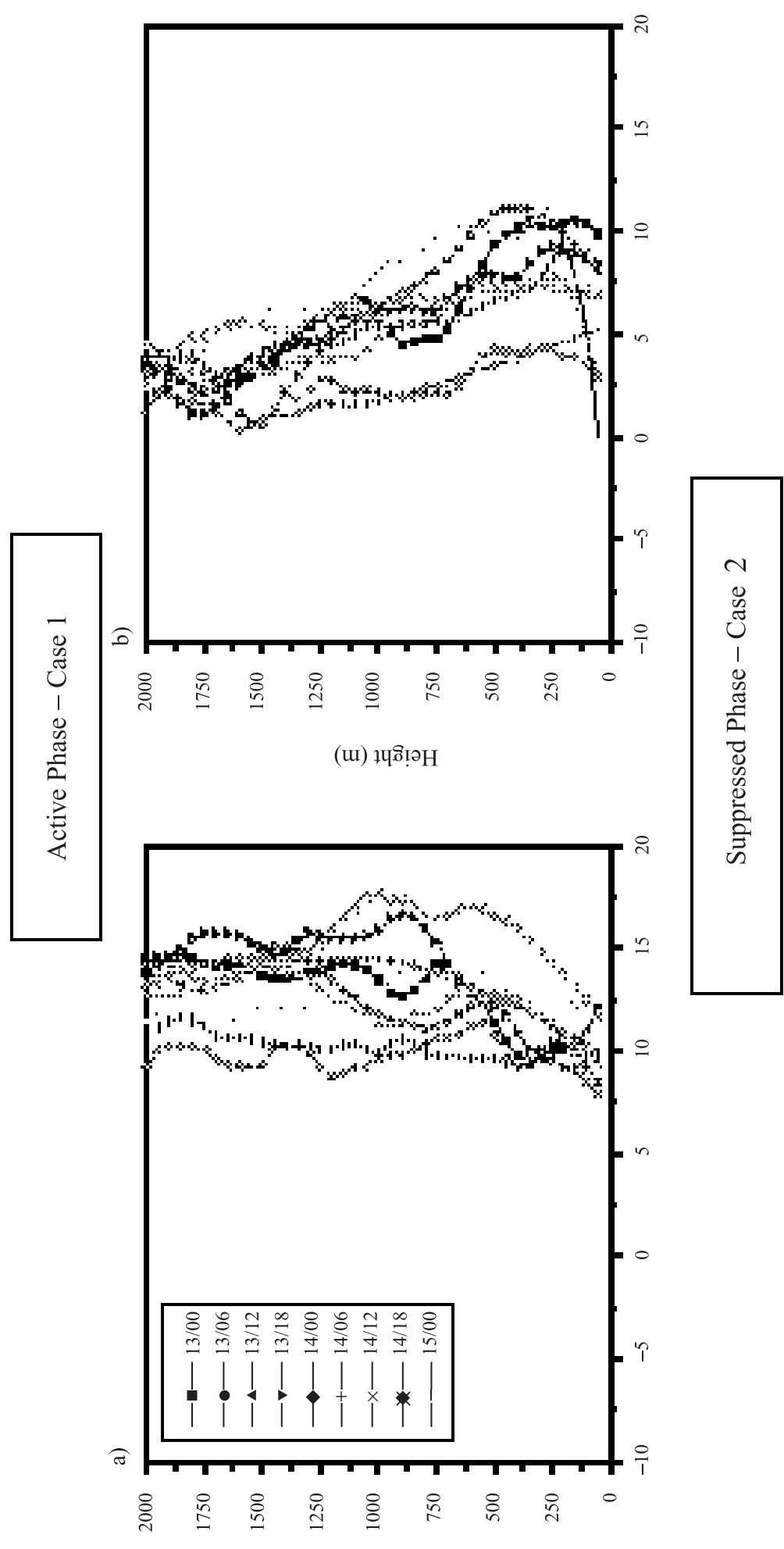

(u) ไบชิเซอH

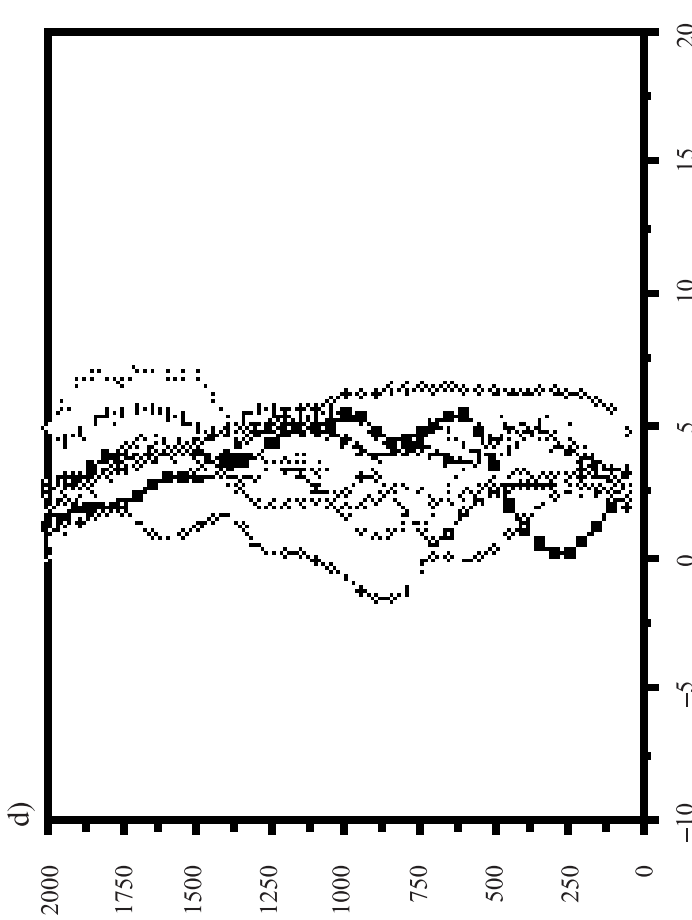

(u)

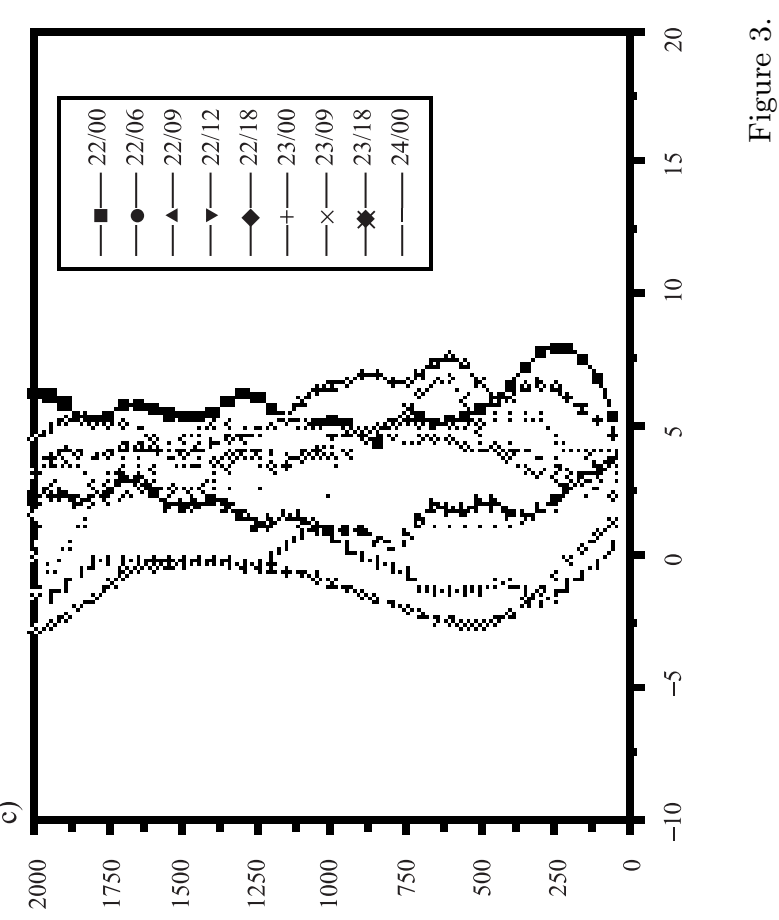

(u) $+48 ิ !$ 


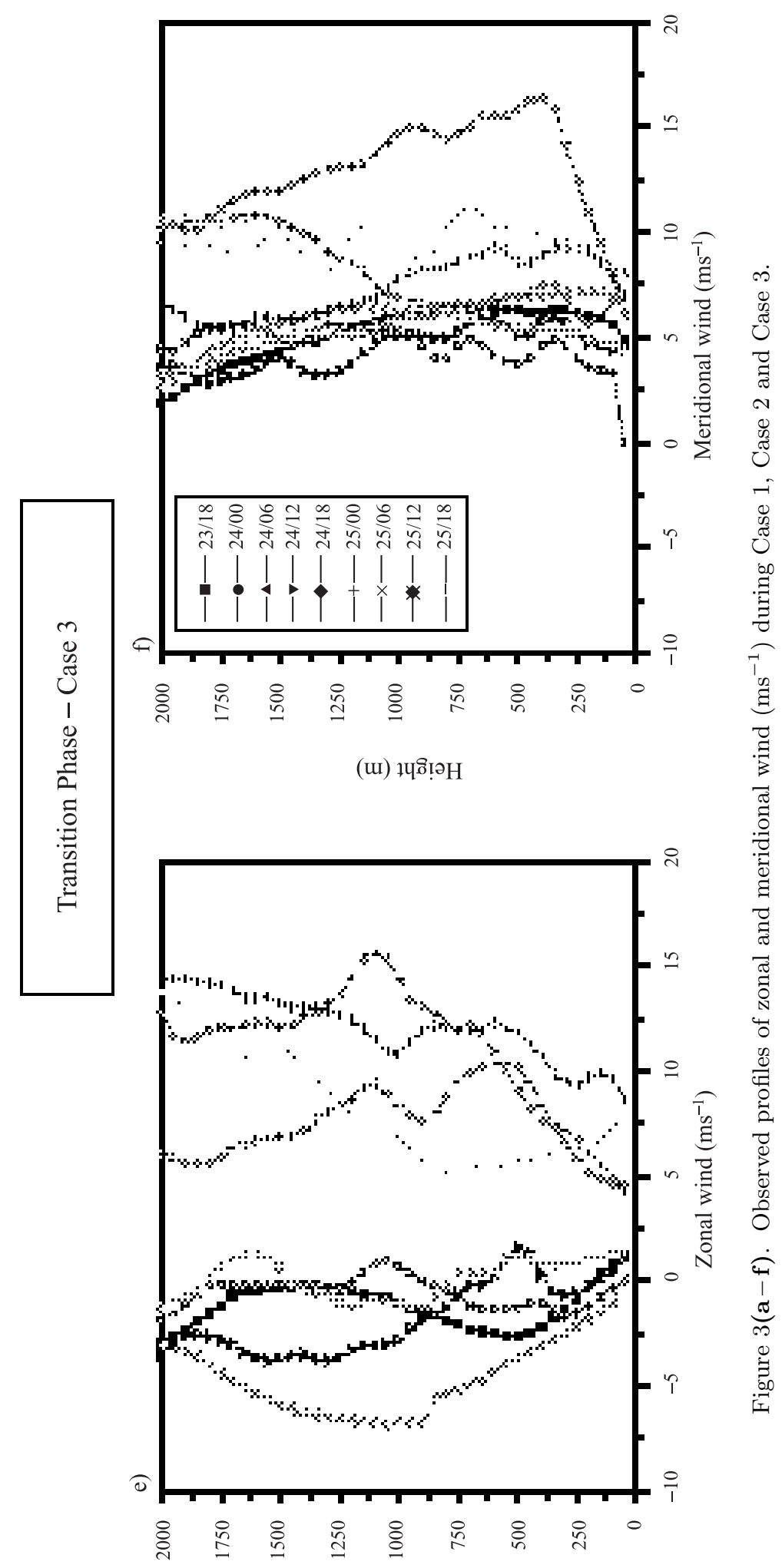

(u) $า 4 จ$ 
Table 1. Overview of the model.

\begin{tabular}{ll}
\hline Model description & 1-D PBL Model with one and half order TKE- $\varepsilon$ closure scheme. \\
\hline Vertical domain & Surface to $2000 \mathrm{~m}$. \\
\hline Vertical levels & $40, \Delta Z=50 \mathrm{~m}$. \\
\hline Independent variables & $Z, t$ \\
\hline Prognostic variables & $U, V, \theta, q, q_{w}, E, \varepsilon$ \\
\hline Diagnostic variables & $K_{u}$ \\
\hline Numerical scheme & Second order accuracy \\
\hline Time integration & Implicit, $\Delta t=600$ seconds. \\
\hline Boundary conditions & For lower boundary, Monin-Obukhov similarity theory. \\
& For upper boundary, the geostrophic conditions, actual observed values \\
& at $2000 \mathrm{~m}$ for TKE, $\varepsilon$, zero energy flux at 2000 m. \\
\hline Physical processes & Dry and moist convective adjustment. \\
& Sensible and latent heat fluxes. \\
& Fluxes under stormy conditions. \\
& Long-wave and short-wave radiation fluxes. \\
\hline
\end{tabular}

momentum, heat and moisture in the interfacial layer, the Boussinesq hypothesis is used,

$$
\overline{a^{\prime} w^{\prime}}=K_{a} \frac{\partial a}{\partial z},
$$

where $a$ is any of the prognostic variables $u, v, \theta, q$ and $q_{w}$, and $K_{a}$ is the eddy exchange coefficient. It is assumed that $K_{a}=\alpha_{a} K$ where $\alpha_{a}$ is a dimensionless constant (equal to unity for the momentum flux). The coefficient $K$ is related to the turbulent kinetic energy $E$ and the dissipation rate $\in$ by the Kolmogrov (1942) equation,

$$
K=\frac{C_{k} E^{2}}{\varepsilon},
$$

where $C_{k}$ is a dimensionless constant. Since in the constant flux layer (a layer of nearly $50 \mathrm{~m}$ from the ocean surface), the turbulent fluxes are nearly constant, it is customary to represent the lower boundary as the maximum height for the variables $\bar{u}, \bar{v}, \bar{\theta}, \bar{q}$ and $\bar{\varepsilon}$ at the constant flux layer height, which, in order are -

$$
\begin{aligned}
& K_{u}\left(\frac{\partial \bar{u}}{\partial z}-\gamma_{u}\right)=C_{D}|V| \bar{u} \\
& K_{v}\left(\frac{\partial \bar{v}}{\partial z}-\gamma_{v}\right)=C_{D}|V| \bar{v} \\
& K_{\theta}\left(\frac{\partial \bar{\theta}}{\partial z}-\gamma_{\theta}\right)=C_{\theta}|V|\left(\bar{\theta}-\bar{\theta}_{s}\right), \\
& K_{q}\left(\frac{\partial q}{\partial z}-\gamma_{\theta}\right)=C_{\theta}|V|\left(\bar{q}-\bar{q}_{s}\right), \\
& \bar{e}=\left(\frac{K_{u}}{l}\right)^{2},
\end{aligned}
$$

where $C_{D}$ (drag) $C_{\theta}$ (heat exchange) are coefficients that are calculated based on MoninObukhov similarity theory. In the vertical, the maximum height of the turbulent boundary layer (which is the top of the PBL) is chosen as the upper boundary. Then, at the top of the boundary layer, the wind speeds, the potential temperature and the moisture attain the values at that height. The turbulent energy flux is assumed to vanish at that height.

Accordingly at $H=2000 \mathrm{~m}$,

$$
\begin{aligned}
\bar{U} & =U_{H}, \\
\bar{V} & =V_{H}, \\
\bar{\theta} & =\theta_{H}, \\
\bar{q} & =q_{H}, \\
\frac{\partial \bar{e}}{\partial z} & =0 .
\end{aligned}
$$

Initial conditions for Case 1, are prepared using the interpolated vertical profiles obtained on 13th August 1999, 00 UTC and the model is integrated for 48 hours. Similarly, for Case 2, the model is initialized on 22nd August 1999 at 00 UTC and integrated for 48 hours. For Case 3, again the model was initialized using the observed profiles on 24th August 1999 at 00 UTC and was integrated for 48 hours. The model was integrated with a time step of $10 \mathrm{~min}$ and at every 6 hours, the simulated outputs are archived for comparison with the observations and discussed in the following section.

\section{Results and discussions}

\subsection{Surface fluxes and $M B L$ height}

The diurnal variation of the model simulated surface fluxes are presented in figure 4 for all the three 
cases, viz., Case 1 (figure 4 a and b), Case 2 (figure $4 \mathrm{~d}$ and e) and Case 3 (figure $4 \mathrm{~g}$ and $\mathrm{h}$ ). On comparing all the three cases, it is found that the sensible heat flux is highest $\left(\sim 75 \mathrm{Wm}^{-2}\right)$ in Case 1 (active convection) and least $\left(\sim 7.5 \mathrm{Wm}^{-2}\right)$ in Case 2 (suppressed convection), while in Case 3 (transition period) it is noticed that the sensible heat flux is below $10 \mathrm{Wm}^{-2}$ during the first 24 hours of integration. After that there is a sudden rise in the sensible heat flux $\left(\sim 57.5 \mathrm{Wm}^{-2}\right)$ as the atmosphere begins to be convectively active. The latent heat flux too, follows a similar trend as the sensible heat flux with Case 1 showing a maximum value of $235 \mathrm{Wm}^{-2}$, Case 2 yielding a low value of $70 \mathrm{Wm}^{-2}$ and Case 3 initial low value of $50 \mathrm{Wm}^{-2}$ and then increasing to $140 \mathrm{Wm}^{-2}$.

These simulated surface fluxes are in a good agreement with the relevant synoptic situation. Additionally, the surface fluxes show distinct diurnal variation in Case 1 and Case 3, whereas, the outcome of Case 2 has shown least diurnal amplitude. This damped diurnal variation (suppressed convection) is consistent with the observations and can be attributed to the low surface winds $\left(\sim 4 \mathrm{~ms}^{-1}\right)$, thereby reducing the transport of the fluxes due to lower gradient. This variation in the surface fluxes discussed above would directly modulate the MBL heights.

In the model, the height of the MBL is taken as the model level at which the turbulences cease to exist in the vertical for the TKE- $\varepsilon$ closure scheme. The variation of the MBL height is plotted with respect to the simulation hours in UTC on the abscissa. For example in Case 1, the first hour of simulation corresponds to 00 UTC on 13th August 1999. Figure 4 (c, f and i) presents the variation of the MBL height during Case 1, Case 2, and Case 3 respectively. Along with the 1-D simulated MBL heights, estimated boundary layer heights (corresponding to model simulations) using derived profiles of $\theta$ and $\theta_{e}$ described as "estimated theta" and "estimated theta-e" are also plotted for all the three cases. Consistent with the sensible heat flux variation, it is found that Case 1 and Case 3 have maximum MBL heights, while Case 2 has the lowest MBL heights. The peak day time MBL heights for these three different cases are $\sim 750 \mathrm{~m}$ (06 UTC, 13th August 1999, 1-D simulated and estimated from $\theta$ ) and $\sim 820 \mathrm{~m}$ (06 UTC, 13th August 1999, estimated from $\theta_{e}$ ) for Case $1 ; \sim 350 \mathrm{~m}$ (09 UTC, 22nd August 1999, 1-D simulated), $\sim 500 \mathrm{~m}$ (estimated from $\theta$ at 09 UTC, 22nd August 1999) and $\sim 510 \mathrm{~m}$ (12 UTC, 22nd August 1999, estimated from $\left.\theta_{e}\right)$ for Case 2; and for Case 3, $\sim 1125 \mathrm{~m}$ (00 UTC, 26th August 1999, 1-D simulated), $\sim 625 \mathrm{~m}$ (18 UTC, 25th August 1999, estimated from $\theta$ ) and $\sim 1300 \mathrm{~m}$ (00 UTC, 26th August 1999, estimated from $\theta_{e}$ ). Higher MBL heights are observed from the estimations of $\theta_{e}$ profile as the effect of moisture content in the atmosphere also contributes to the growth of MBL height.

Unlike the variation in the surface fluxes, the MBL heights do not show any systematic diurnal variation. The estimated MBL heights (estimated from $\theta$ ) overlaid on the predicted MBL height curve are in general agreement. In Case 1 (active convection) and Case 3 (transition period) a fair agreement is noticed between the estimated (from $\theta$ and $\theta_{e}$ ) and the model predicted MBL values. There is also an overall agreement in terms of the actual numerical value and the temporal variation of the MBL heights. However, there is a slight difference in the estimated MBL for Case 2 (suppressed convection) and the corresponding model simulated values. Typical estimated values are of the order of $250 \mathrm{~m}$ (estimated from $\theta$ profiles) and $350 \mathrm{~m}$ (estimated from $\theta_{e}$ profiles) while the predicted MBL height is averaged around $150 \mathrm{~m}$ during the suppressed convective episode. The MBL heights predicted in the model are directly related to the predicted sensible heat fluxes while the estimated MBL heights (both estimated from $\theta$ and $\theta_{e}$ ) can be significantly influenced by lower surface winds and hence advection. The underestimation of model predicted MBL heights can therefore, be attributed to the inhomogeneity and the part played by advection, which cannot be resolved in a 1-D simulation.

\subsection{TKE evolution}

The TKE evolution and its variation is an important parameter that is simulated by the model but not observed. TKE is taken as a measure of turbulence intensity in the boundary layer and responsible for various processes in the boundary layer such as entrainment, stability and effective transport of fluxes under low wind conditions (due to buoyancy). Figure 5 (a, d and g) shows the variation of the total turbulent kinetic energy with time and height, for Case 1, Case 2 and Case 3 respectively. As expected, a higher value of TKE is found in Case 1 and Case 3, while a lower value of TKE is noticed in Case 2. Interestingly, the maximum value of total TKE $\left(\sim 0.65 \mathrm{~m}^{2} \mathrm{~s}^{-2}\right)$ is predicted for the nighttime (Case 1) and late evening time (Case 3). This could be due to the cooling of the air after sunset, while the SST being constant leading to higher sensible heat flux transport and hence the generation of turbulence. This is consistent with the observed synoptic situation. On the other hand in the suppressed convection regime (Case 2), a totally 


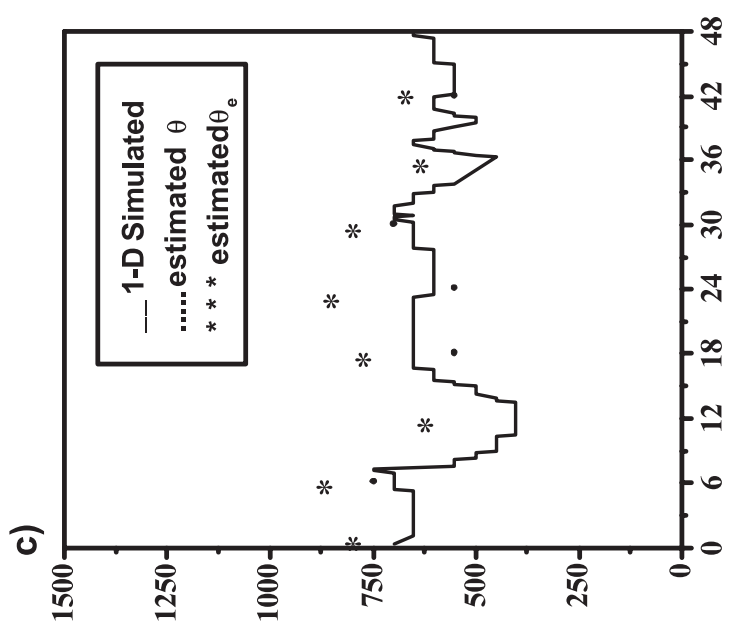

(w) ㄴํำH TgW
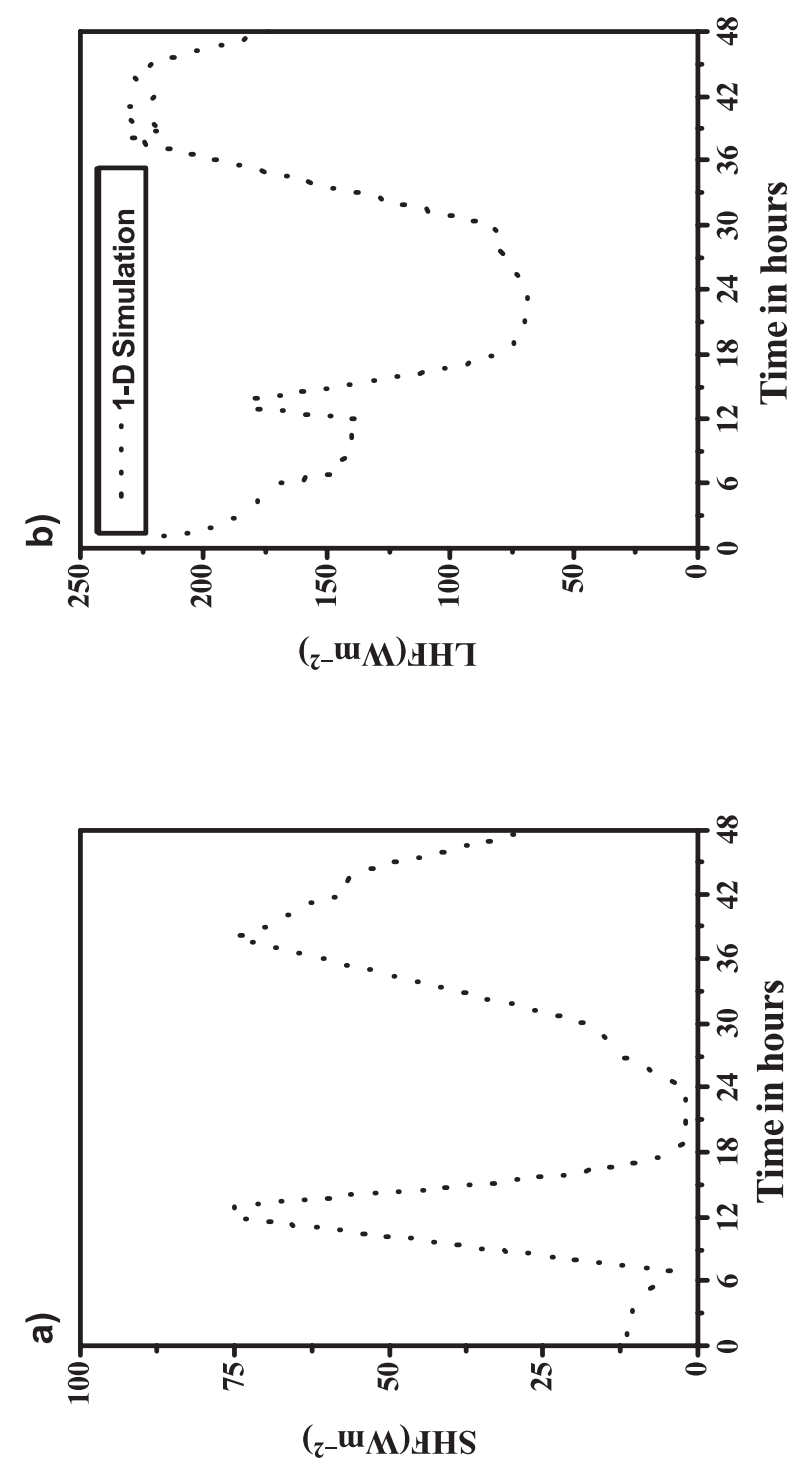

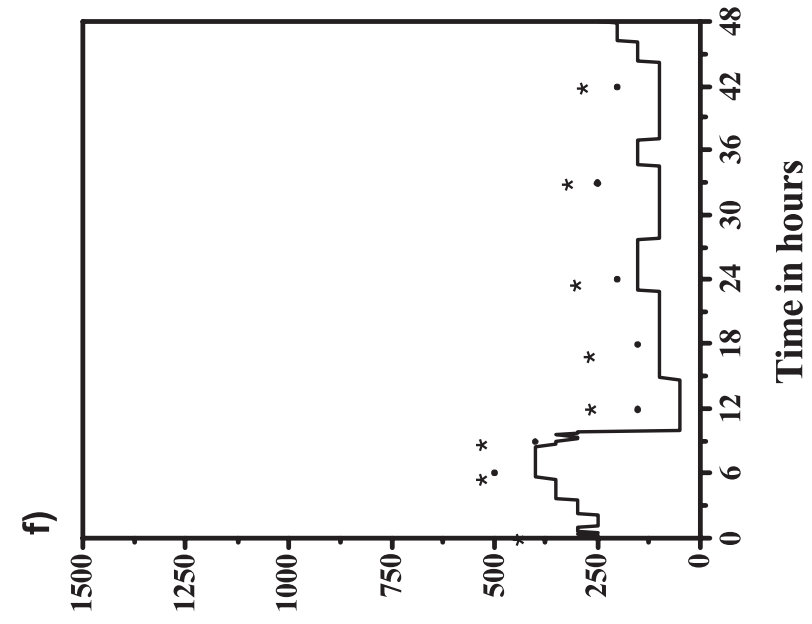

(w) 74ริ!ว4 TЯW
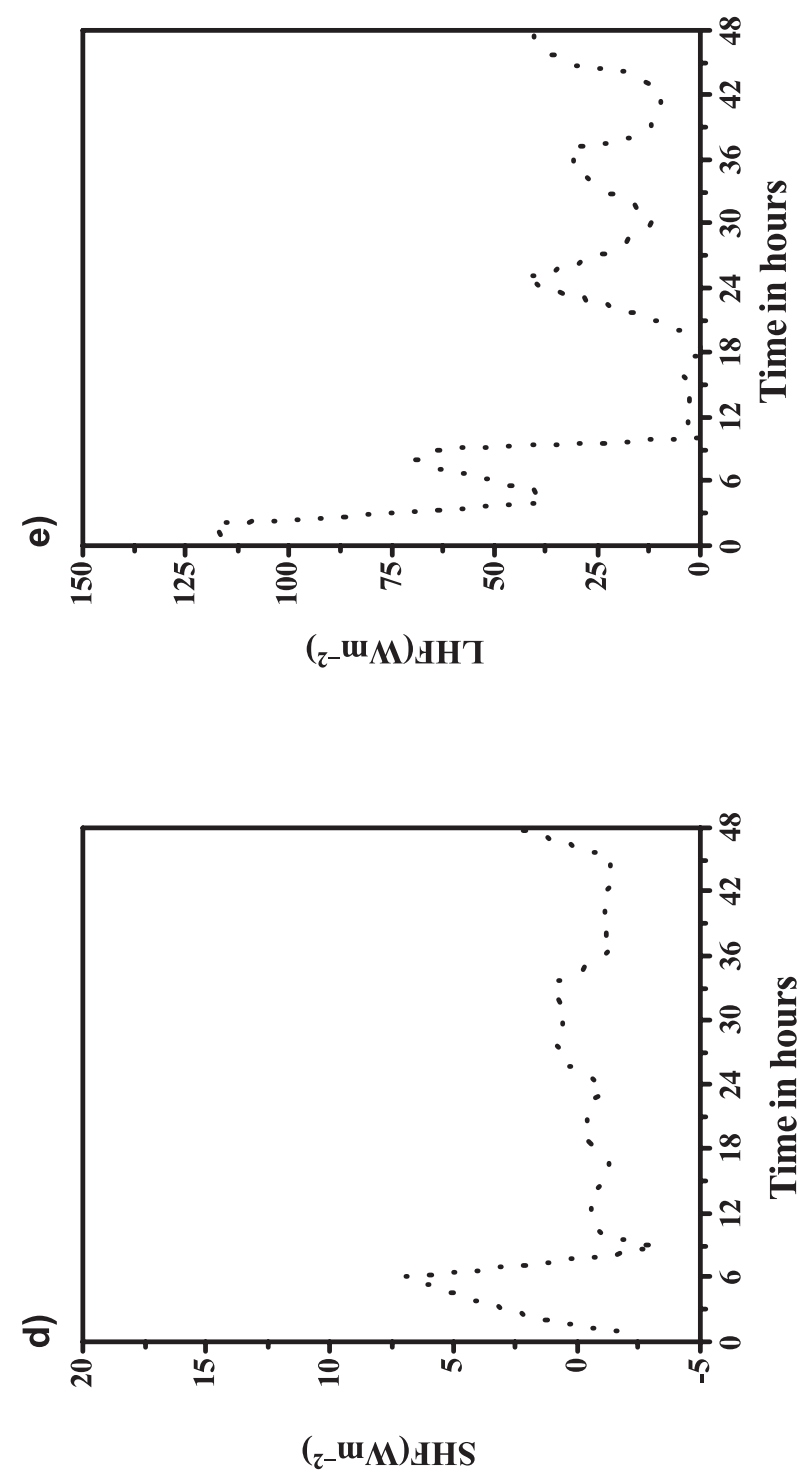

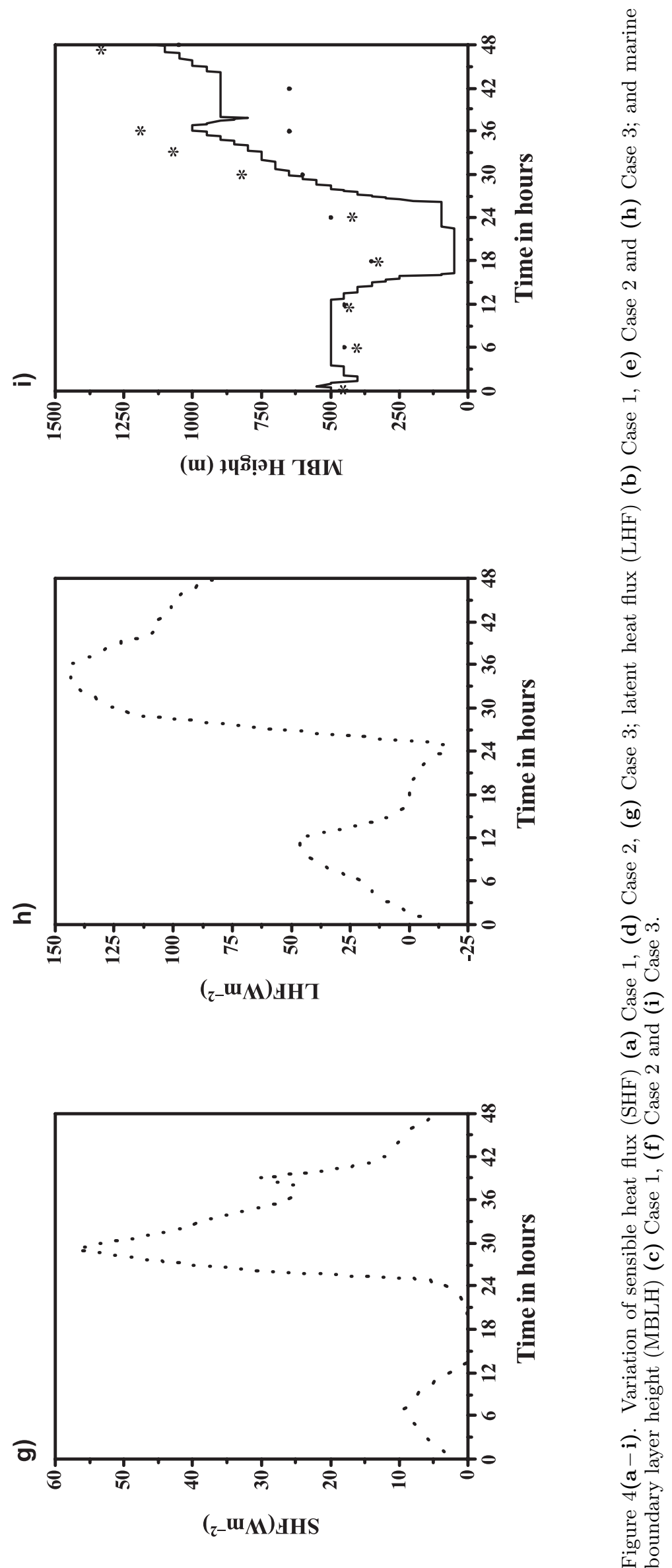

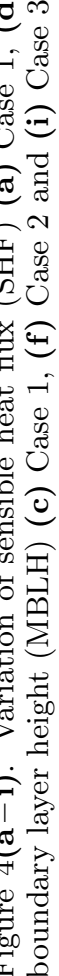



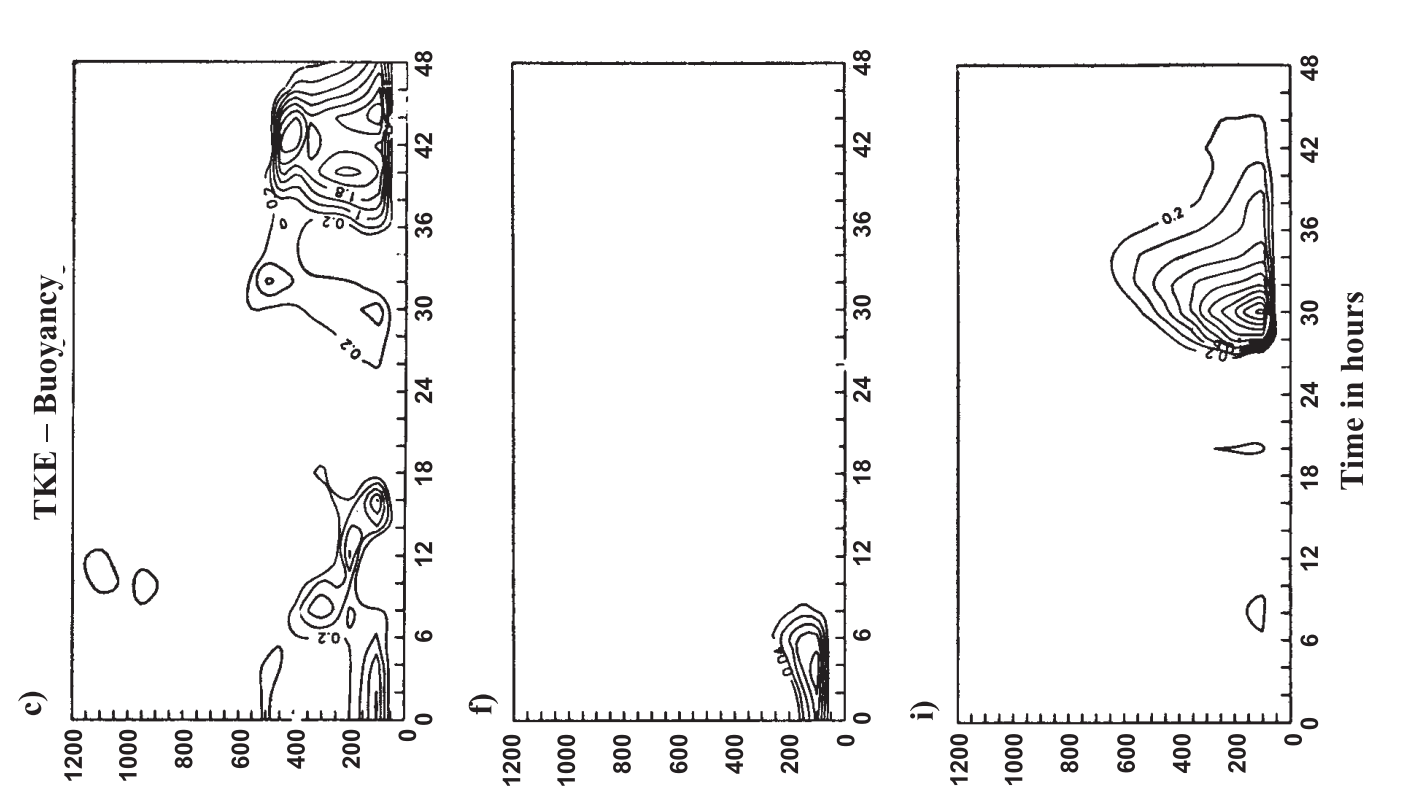

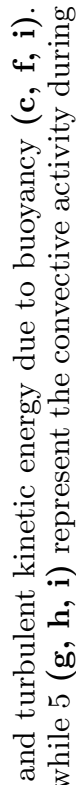
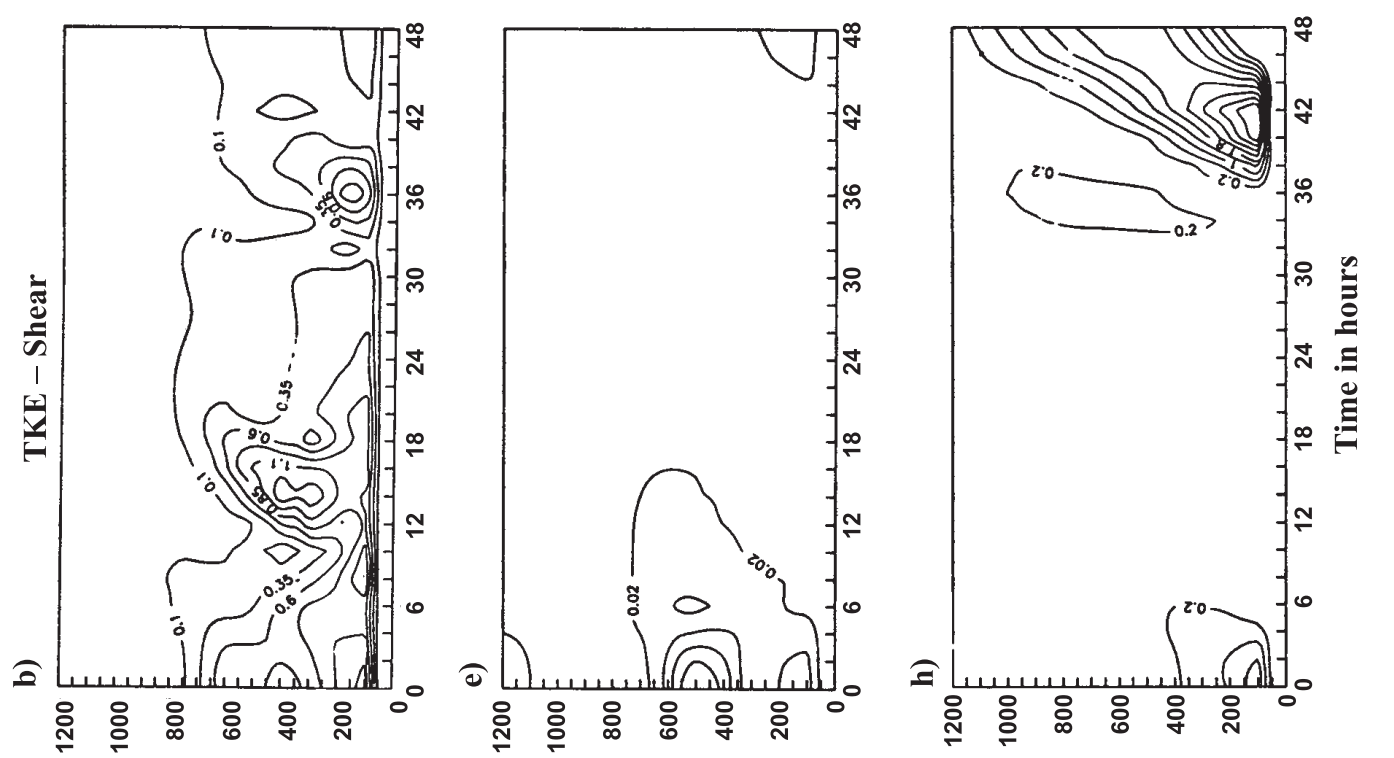

도

o.

อ

范

$\circ$ 융

Ð

के० एक

बै

.

菒

링 웜

कิ

की

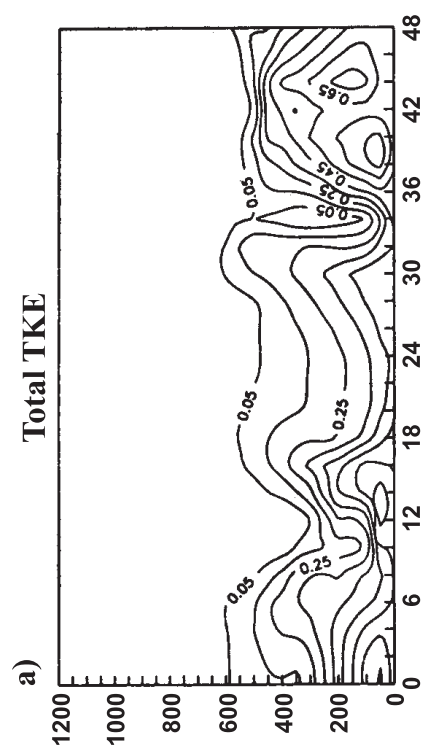

(u) ㄴํำเท

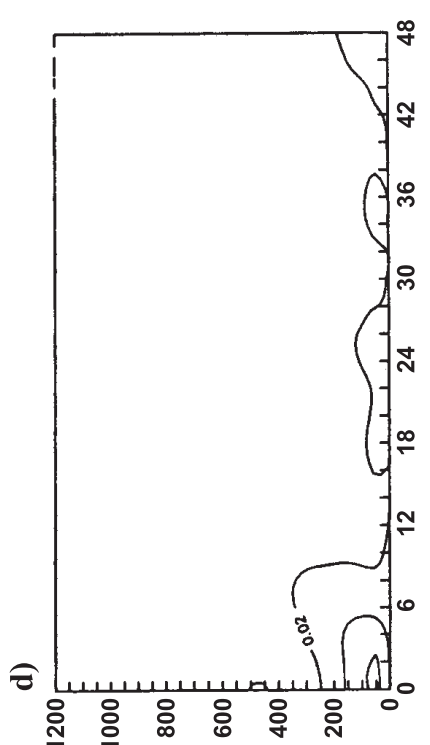

(ui) $748 ็ !$

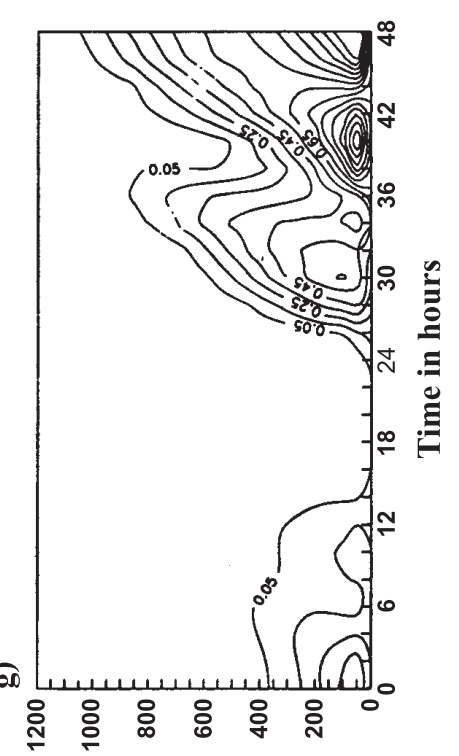

(ui) 748
ชी

కే

के के

¿

.

궁

牙:

릴

:

$\exists$

표유

㟧

웅웜

응

里完.

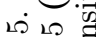

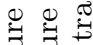

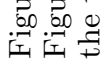



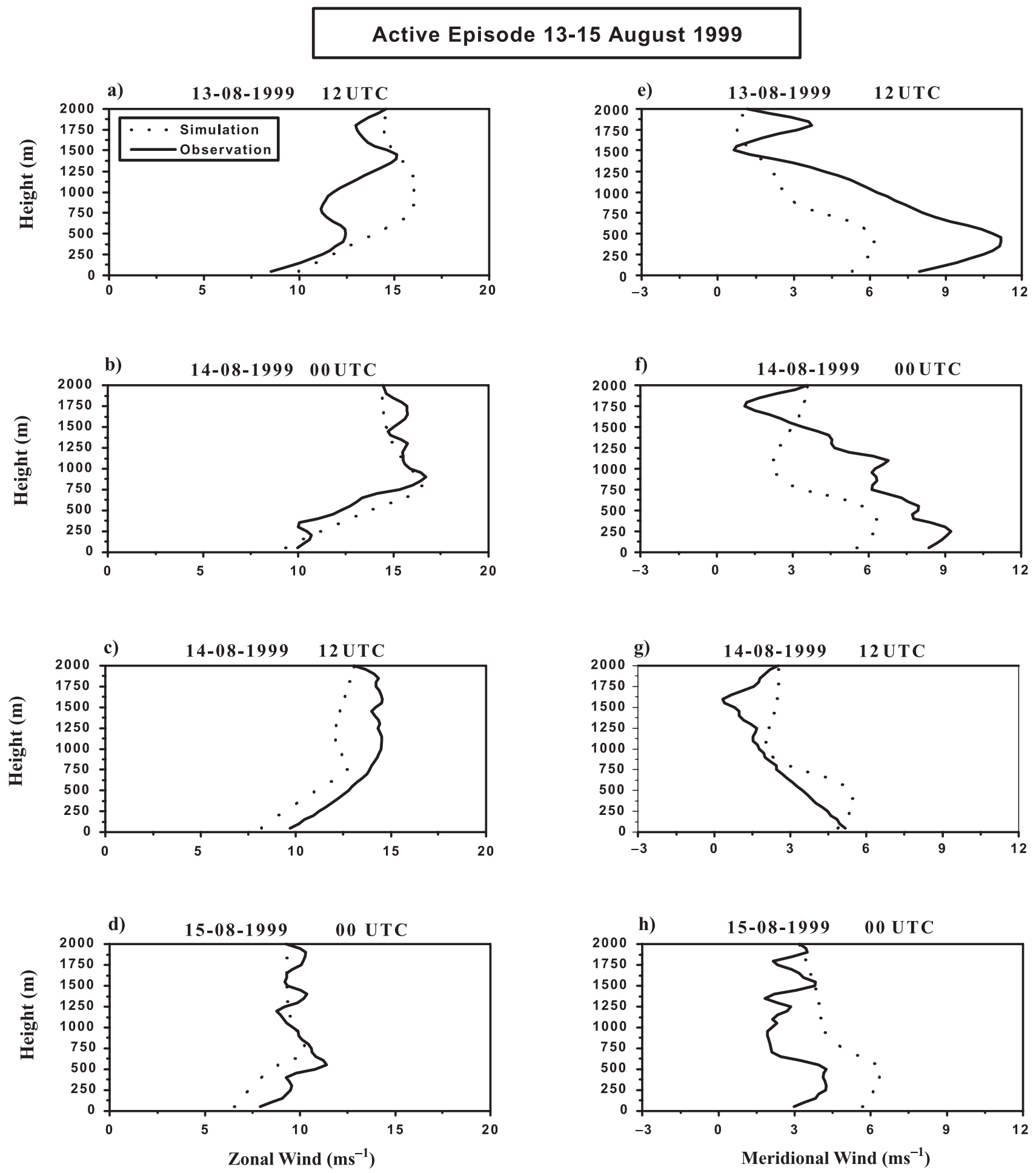

Figure 6. (A) Vertical profiles of zonal and meridional wind $\left(\mathrm{ms}^{-1}\right)$ for Case 1.

opposite scenario is seen, with virtually calm atmosphere.

Figure 5 (b and c) (Case 1), 5 (e and f) (Case 2) and 5 (h and i) (Case 3) respectively show the contribution due to shear and buoyancy separately. From figure 5(b) and 5(c) of Case 1, one can notice that shear production $\left(\sim 1.1 \mathrm{~m}^{2} \mathrm{~s}^{-2}\right)$ is highest during daytime while the

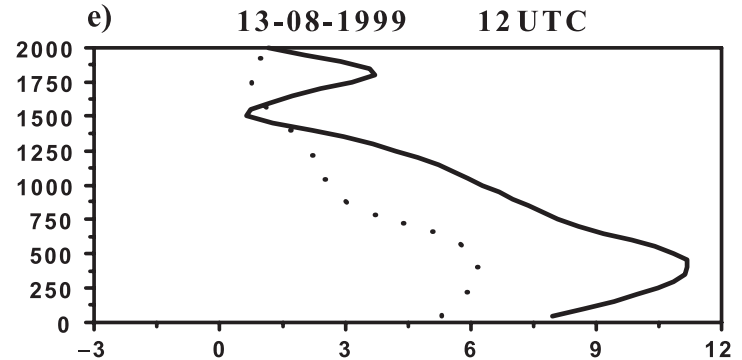

$$
2
$$




\section{Active Episode 13-15 August 1999}
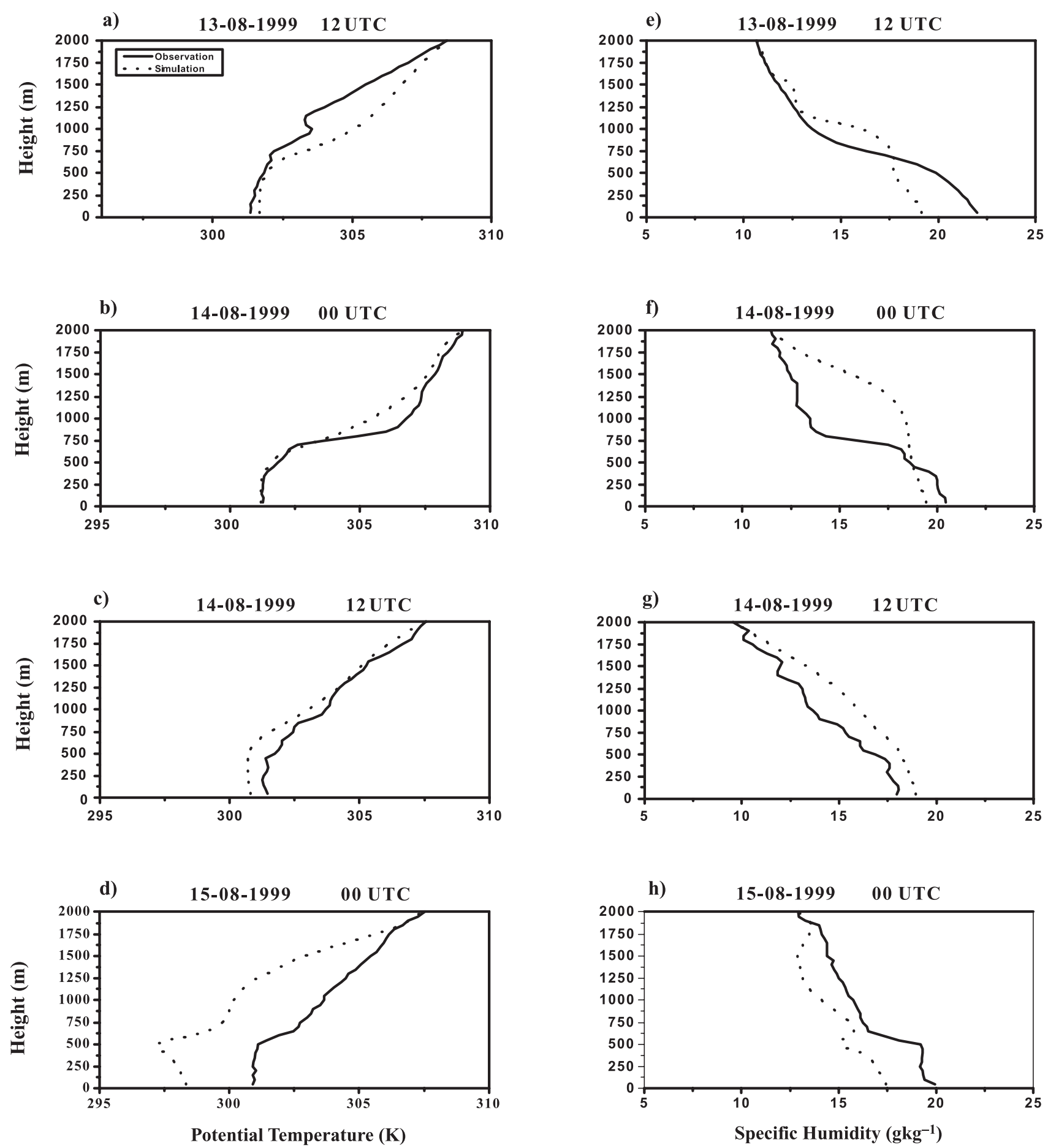

Figure 6. (B) Vertical profiles of potential temperature and specific humidity $\left(\mathrm{gkg}^{-1}\right)$ for Case 1.

$\mathrm{d}$, e and $\mathrm{f}$ ), owing to clear and calm atmosphere and low surface winds, virtually no TKE generation is noticed, which is well simulated by the model.

\subsection{Model validation}

The model simulated and the observed vertical profiles of zonal and meridional wind, potential tem- 


\section{Suppressed Episode 22-24 August 1999}
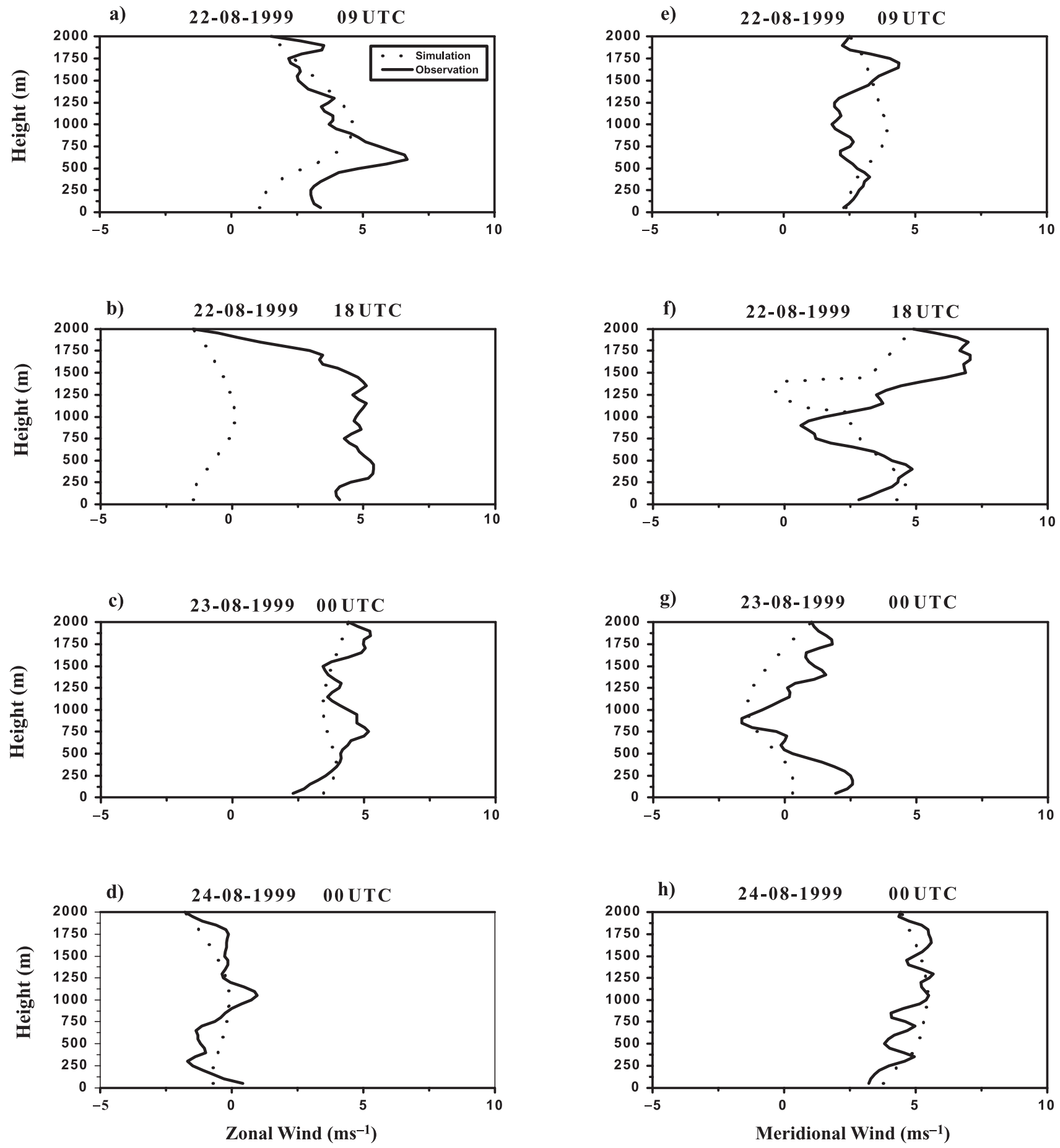

Figure 7. (A) Vertical profiles of zonal and meridional wind $\left(\mathrm{ms}^{-1}\right)$ for Case 2.

perature and specific humidity are presented in figures $6-8$. Considering all the three cases, the model simulated winds and the specific humidity profiles are in fair agreement with the observations and especially the potential temperature profiles are in good agreement. For example, the simulated zonal wind profile (figures $6 \mathrm{~A}$ and $\mathrm{B}$ ) captures very well the jet like feature (at $\sim 900 \mathrm{~m}$ ), which is noticed in the observed profile. Although there are differences between the observed and model simulated 


\section{Suppressed Case 22-24 August 1999}
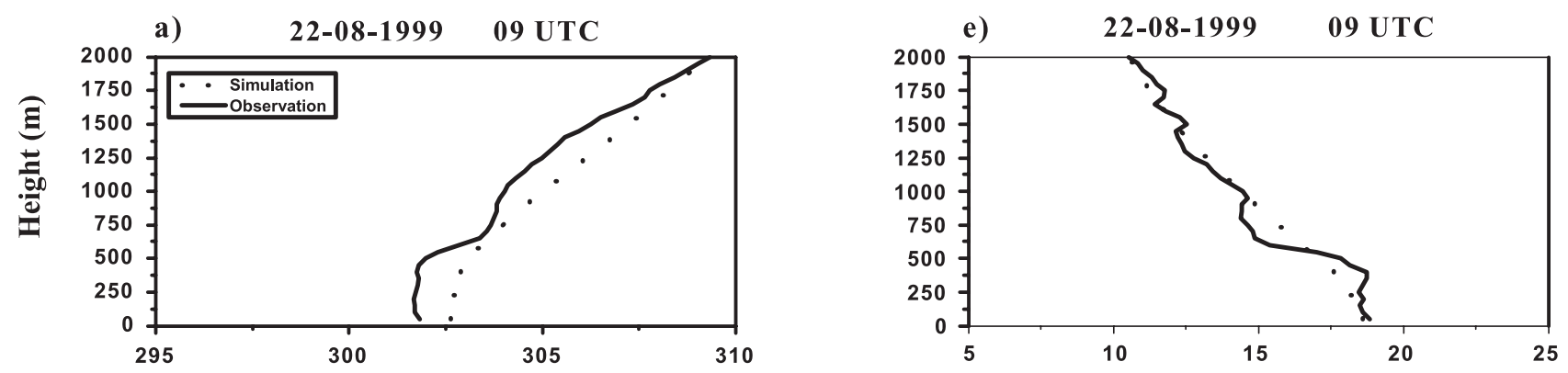

b)

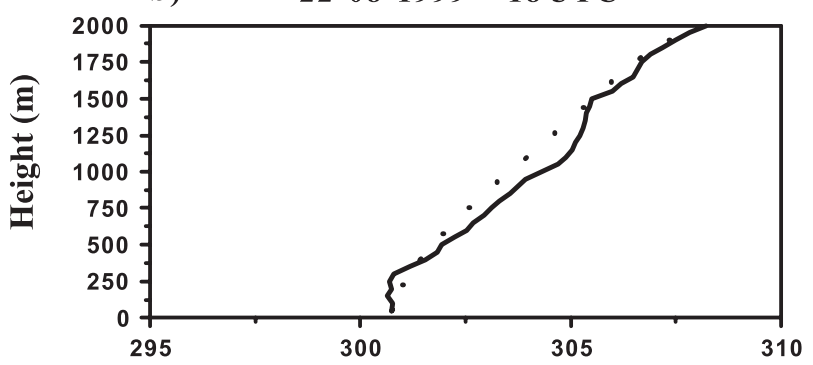

c)
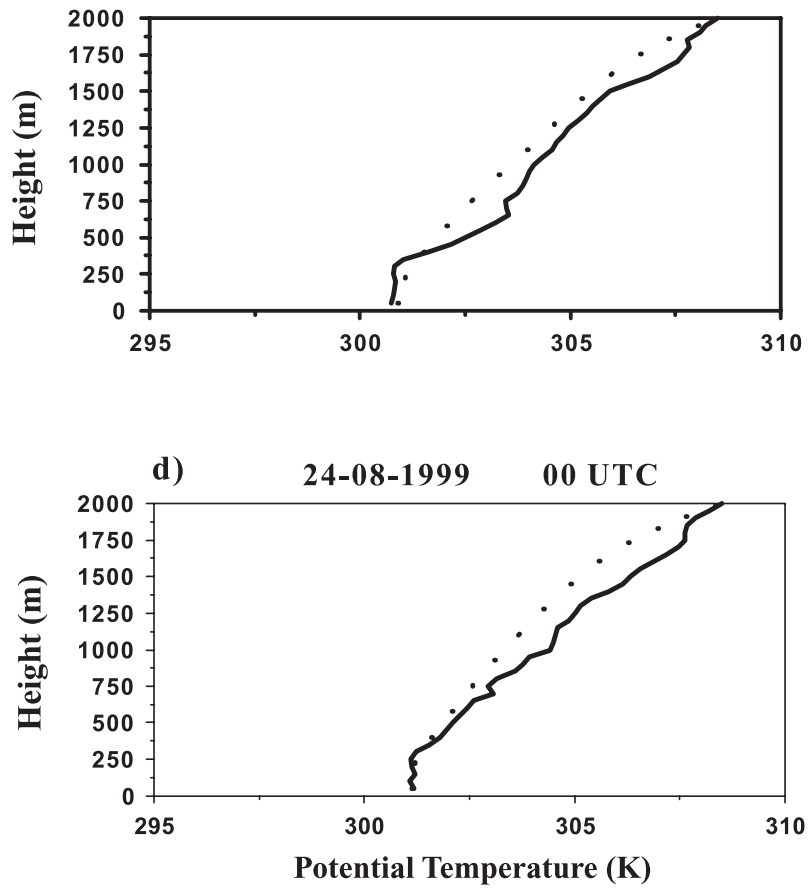

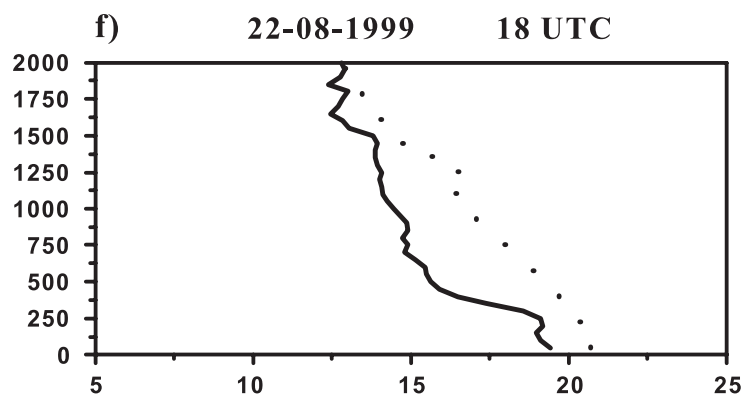

g) 23-08-1999 00 UTC

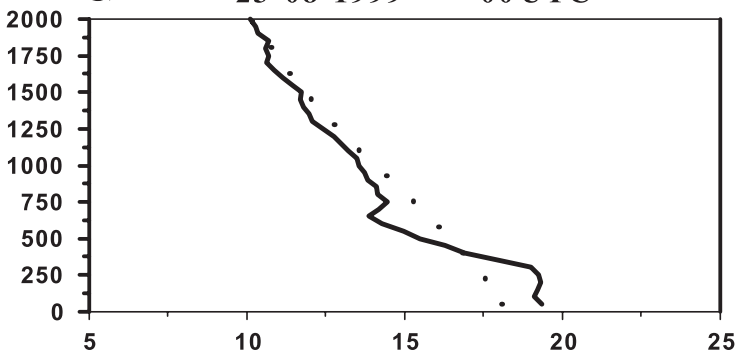

h) 24-08-1999 00 UTC

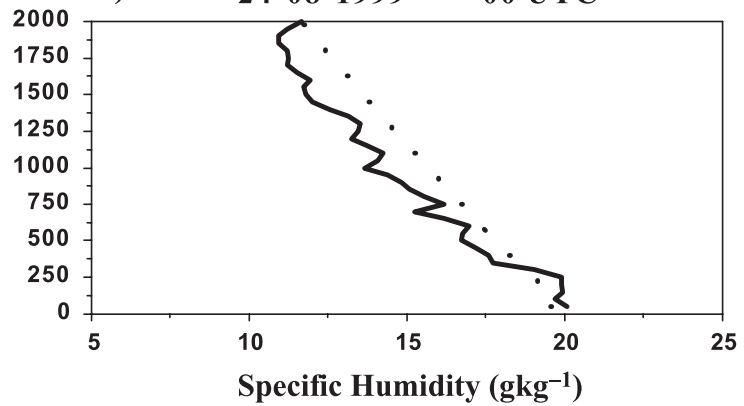

Figure 7. (B) Vertical profiles of potential temperature and specific humidity $\left(\mathrm{gkg}^{-1}\right)$ for Case 2.

values, the trends followed by them agree well with each other. Statistical analysis of the model performance in simulating $u, v, \theta$ and $q$ during the three synoptic situations (Case 1, Case 2 and Case 3 ) are given in table 2. The maximum RMSE (root mean square error) during the convectively active episode (Case 1) for $u, v, \theta$ and $q$ respectively are of the order of 2.49 (36th hour simulation, 12 UTC of 


\section{Transition Period 24-26 August 1999}
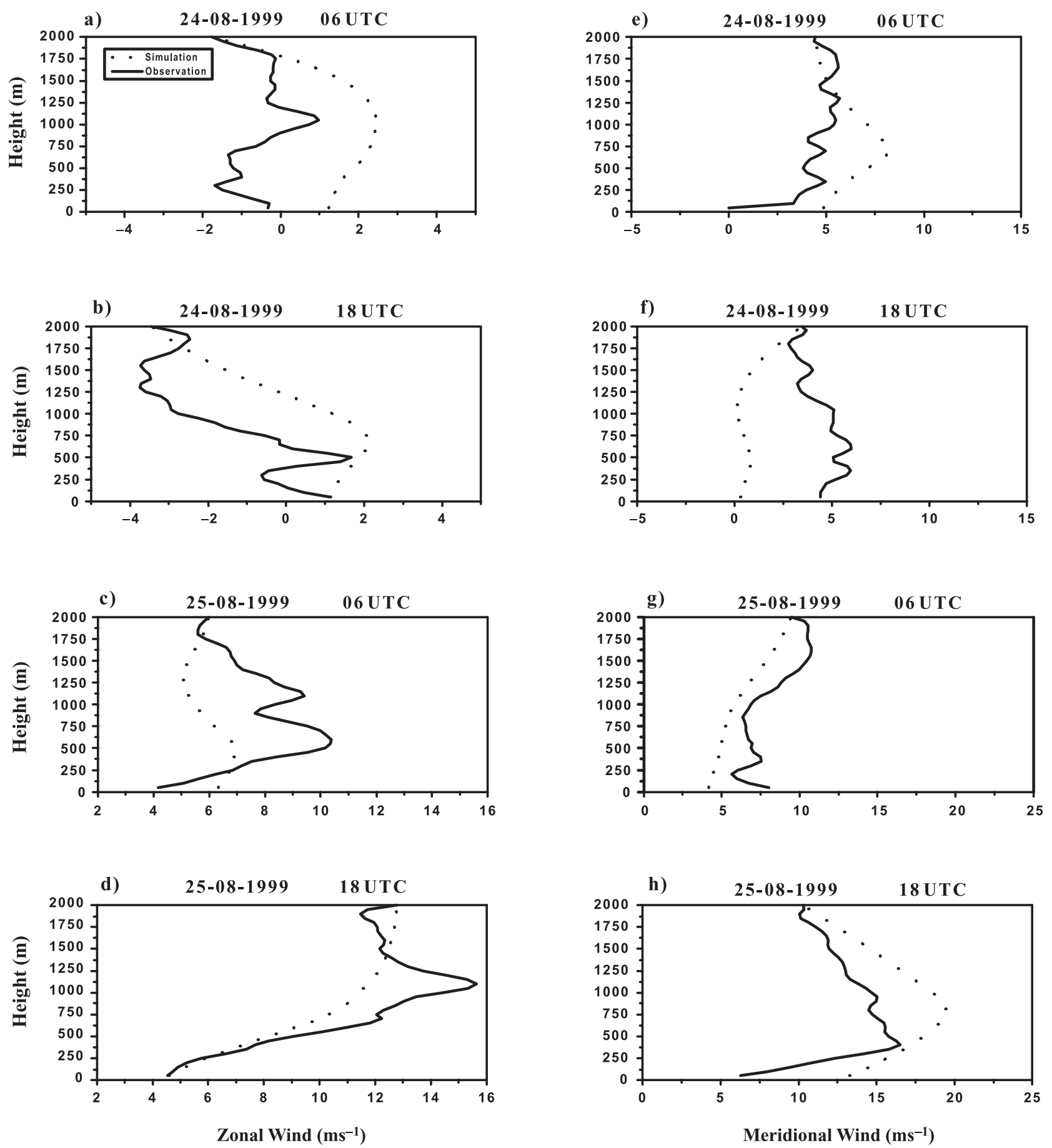

Figure 8. (A) Vertical profiles of zonal and meridional wind $\left(\mathrm{ms}^{-1}\right)$ for Case 3.

14-08-99), 1.91 (12th hour of simulation, 12 UTC of 13-08-99), 0.98 (24th hour of simulation, 00 UTC of 14-08-99) and 1.66 (12th hour of simulation, 12 UTC of 13-08-99). The correlation coefficient for $u, v, \theta$ and $q$ during the same time respectively are
0.87, 0.89, 0.96, and 0.78. For Case 2, the suppressed convection episode, maximum RMSE and correlation coefficients respectively for $u, v, \theta$ and $q$ are 4.38 and 0.50 (18th hour of simulation, 18 UTC of 22-08-99), 4.41 and -0.32 (9th hour simula- 

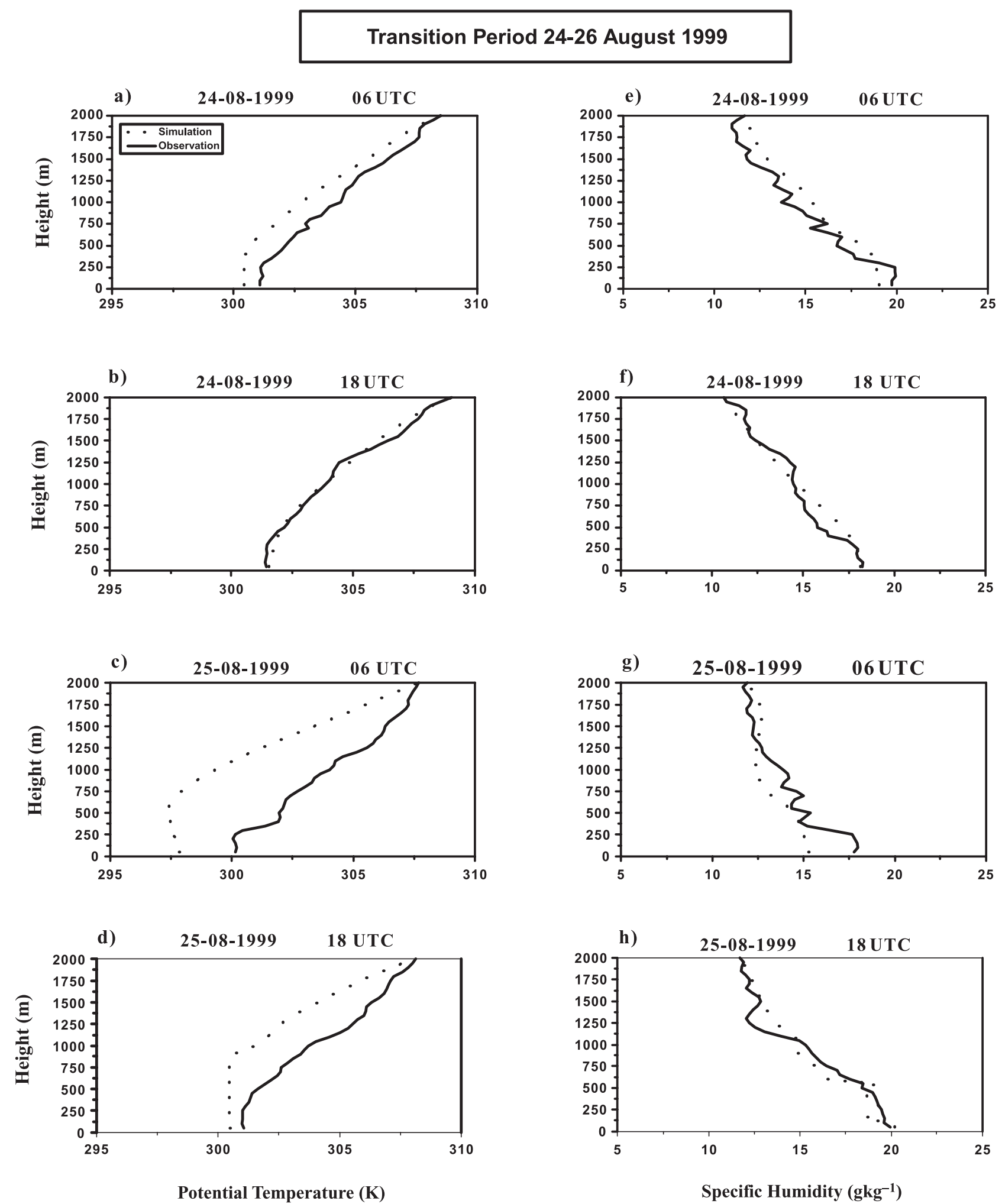

Figure 8. (B) Vertical profiles of potential temperature and specific humidity $\left(\mathrm{gkg}^{-1}\right)$ for Case 2. 
Table 2. Statistical evaluation of the model performance in simulating the zonal wind $\left(u, m s^{-1}\right)$, meridional wind $\left(v, \mathrm{~ms}^{-1}\right)$, potential temperature $(\theta, K)$ and specific humidity $\left(q, g . \mathrm{kg}^{-1}\right)$.

a) Convectively active episode (13th-15th August 1999)

\begin{tabular}{ccccccccc}
\hline \multirow{2}{*}{$\begin{array}{c}\text { Simulation } \\
\text { hour }\end{array}$} & \multicolumn{2}{c}{$u$} & \multicolumn{2}{c}{$v$} & \multicolumn{2}{c}{$\theta$} \\
\cline { 2 - 9 } & CC & RMSE & CC & RMSE & CC & RMSE & CC & RMSE \\
\hline 12 & 0.42 & 1.96 & 0.89 & 1.91 & 0.87 & 0.83 & 0.78 & 1.66 \\
24 & 0.90 & 2.06 & 0.60 & 1.83 & 0.96 & 0.98 & 0.85 & 1.12 \\
36 & 0.87 & 2.49 & 0.87 & 1.27 & 0.99 & 0.72 & 0.75 & 1.58 \\
48 & 0.40 & 1.34 & 0.60 & 1.22 & 0.96 & 0.53 & 0.97 & 0.63 \\
\hline
\end{tabular}

b) Convectively suppressed episode (22nd - 24th August 1999)

\begin{tabular}{ccccccccc}
\hline \multirow{2}{*}{$\begin{array}{c}\text { Simulation } \\
\text { hour }\end{array}$} & \multicolumn{2}{c}{$u$} & \multicolumn{2}{c}{$v$} & \multicolumn{2}{c}{$\theta$} \\
\cline { 2 - 9 } & CC & RMSE & \multicolumn{1}{c}{ CC } & RMSE & CC & RMSE & CC & RMSE \\
\hline 09 & 0.46 & 1.00 & -0.32 & 4.41 & 0.99 & 0.70 & 0.97 & 0.41 \\
18 & 0.50 & 4.38 & 0.55 & 1.44 & 0.99 & 0.00 & 0.92 & 1.76 \\
24 & 0.36 & 0.47 & 0.76 & 1.09 & 0.98 & 0.41 & 0.96 & 0.50 \\
48 & 0.40 & 0.38 & 0.60 & 0.38 & 0.99 & 0.50 & 0.98 & 0.80 \\
\hline
\end{tabular}

c) Transition period (24th-26th August 1999)

\begin{tabular}{ccccccccc}
\hline \multirow{2}{*}{$\begin{array}{c}\text { Simulation } \\
\text { hour }\end{array}$} & \multicolumn{2}{c}{$u$} & \multicolumn{2}{c}{$v$} & \multicolumn{2}{c}{$\theta$} & \multicolumn{2}{c}{$q$} \\
\cline { 2 - 9 } & CC & RMSE & CC & RMSE & CC & RMSE & CC & RMSE \\
\hline 06 & 0.41 & 1.75 & -0.15 & 1.70 & 0.99 & 0.68 & 0.97 & 0.65 \\
18 & 0.70 & 1.98 & -0.51 & 3.43 & 0.99 & 0.00 & 0.91 & 0.41 \\
30 & 0.11 & 2.01 & 0.91 & 1.58 & 0.92 & 3.11 & 0.89 & 0.86 \\
42 & 0.89 & 1.25 & 0.81 & 2.97 & 0.93 & 1.48 & 0.97 & 1.01 \\
\hline
\end{tabular}

tion, 09 UTC of 22-08-99), 0.70, 0.99 (9th hour simulation, 09 UTC of 22-08-99) and 1.76, 0.92 (18th hour of simulation, 18 UTC of 22-08-99). As described for Case 1 and Case 2, maximum RMSE and correlation coefficients during transition period for $u, v, \theta$ and $q$ respectively are $2.01,0.11$ (30th hour of simulation, 06 UTC of $25-08-99$ ), 3.43, - 0.51 (18th hour of simulation, 18 UTC of 24-08-99), 3.11, 0.92 (30th hour of simulation, 06 UTC of 25-08-99) and 1.01, 0.97 (42nd hour of simulation, 18 UTC of 25-08-99). In fact it is quite evident that 1-D model has its own limitations for any given scenario due to non-homogeneity and non-inclusion of advection. Hence some discrepancies are noticed between the simulations and observed values in the regimes of active convection. For example at higher levels $(750-1500 \mathrm{~m})$ the specific humidity is predicted a bit higher $\left(7-8 \mathrm{gkg}^{-1}\right)$ on 14 th August 1999 , at 00 UTC. Moreover the simulated profiles are not able to fully capture some of the sudden fluctuations (as seen in the transition period) observed in the atmosphere. But for the zones of active surface forcing the profiles show a better agreement. Thus in general the model is able to simulate various MBL processes fairly well.

\section{Summary and conclusions}

A numerical 1-D multi-level planetary boundary layer model is successfully applied to simulate MBL characteristics over the Bay of Bengal during the final phase of BOBMEX (1999). Three distinct MBL regimes corresponding to three different synoptic situations (active convection, suppressed convection, transition from suppressed to active convection) are identified based on the surface synoptic observations, satellite imageries, IDWRs, etc. The model is able to capture the characteristic features of all these three distinct regimes of interest. The observed profiles are used to initialize the model and the simulated profiles over a period of 48 hours are compared with the observed profiles.

An MBL height of $750 \mathrm{~m}$ is predicted over the convectively active region and $1125 \mathrm{~m}$ during the transition (dominant convective activity during 25th-26th August 1999) period, which is in good agreement with the estimated MBL heights. However, in the suppressed convection regime, the model generally under-predicted the MBL heights when compared with the estimated ones. This could be due to the non-homogeneity and advection that is not represented in the 1-D 
model. As foreseen, the model could simulate the convectively active boundary layer structure very well than in any other dynamically forced regimes. The interdependence of the TKE and MBL heights is also confirmed from the model results.

The observed vertical profiles of potential temperature and specific humidity are noticed to be in good agreement with the model simulated profiles. Interestingly, the model simulated zonal and meridional winds are also in fair agreement with the observed profiles. As the thermodynamic structure of the MBL is better reproduced than the dynamical fields, it suggests that in order to investigate the meso-scale processes a $3-\mathrm{D}$ model is required. Still, it is worth mentioning that the performance of the 1-D model is fairly promising. Such a model can be used as an instrument over data-sparse regions, along with available sounding data to generate time-varying representative fields. Thus, these simulated profiles can be actively used to enhance the $3-\mathrm{D}$ analysis, that along with a meso-scale model can be applied to study various processes in the marine atmosphere, viz., transport, entrainment etc., over a region. In addition to that, such a validated model can be linked to a 1-D ocean model (making a coupled model), to study the coupled response of the marine environment such as SST and the mixed layer of the ocean with the MBL characteristics (Gadgil et al 1984)

\section{Acknowledgements}

The authors sincerely acknowledge the Council of Scientific and Industrial Research (CSIR) for providing partial financial support and the Department of Science and Technology (DST) Govt. of India for facilitating the participation and obtaining of BOBMEX-99 data sets. We also thank the scientific team onboard ORV Sagar Kanya, in particular Dr. G S Bhat, for providing part of the BOBMEX-99 data. The authors acknowledge the India Meteorological Department (IMD) for providing the surface and upper air observations from the coastal stations of India. We also thank the anonymous reviewers' for their valuable comments and suggestions.

\section{References}

Bhat G S, Gadgil S, Hareesh Kumar P V, Kalsi S R, Madhusoodan P, Murty V S N, Prasada Rao C V K, Ramesh Babu V, Rao L V G, Rao R R, Ravichandran M, Reddy K G, Sanjeeva Rao P, Sengupta D, Sikka D R, Swain J and Vinaychandran P N 2001 BOBMEX: The Bay of Bengal Monsoon Experiment; Bull. Am. Meteor. Soc. 82 2217-2243

Bhat G S, Chakraborty A, Nanjundiah R S and Srinivasan J 2002 Vertical thermal structure of the atmosphere during active and weak phases of convection over the north Bay of Bengal: Observation and model results; Curr. Sci. $\mathbf{8 3}$ 296-302

Emmanuel K A 1994 Atmospheric Convection, (Oxford: Oxford University Press)

Gadgil S, Joseph P V and Joshi N V 1984 Ocean-atmosphere coupling over monsoon regions; Nature 312 141-143

Godfrey J S and Lindstorm E J 1989 On the heat budget of equatorial west Pacific surface mixed layer; J. Geophys. Res. 94 8007-8017

Holton J R 1992 An Introduction to Dynamic Meteorology, (London: Academic Press) pp. 58-86

Kolmogrov A N 1942 Incompressible fluid turbulent motion equations; Izv. Akad. Nauk SSSR, Ser. Fiz 6 56-58

Lykossov V N and Platov G A 1992 A numerical model of interaction between atmospheric and oceanic boundary layers; Russ. Numer. Anal. Math. Modelling 7 419-440

Neelin J D, Held I M and Crook K H 1987 Evaporationwind feedback and low frequency variability in the tropical atmospheres; J. Atmos. Sci. 44 2341-2345

Satyanarayana A N V, Mohanty U C and Sam N V 1999 A study on marine boundary layer processes in the ITCZ and non-ITCZ regimes over Indian Ocean with INDOEX IFP-99 data; Curr. Sci. $\mathbf{7 6} 890-897$

Satyanarayana A N V, Mohanty U C, Sam N V, Basu S and Lykossov V N 2000 Numerical simulation of the marine boundary layer characteristics over the Bay of Bengal as revealed by BOBMEX-98 Pilot Experiment; Proc. Indian Acad. Sci. (Earth Planet. Sci.) 109 293-303

Sikka D R and Gadgil S 1980 On the maximum cloud zone and the ITCZ over the Indian longitudes during the southwest monsoon; Mon. Weather Rev. 108 18401853

Shinoda T, Hendon H H and Glick J D 1998 Intra-seasonal sea surface temperature variability in the tropical Pacific and Indian Ocean; J. Climate 11 1685-1702

Thapliyal V, Desai D S and Krishnan V 2000 Weather in India, Monsoon Season (June-September 1999); Mausam $51285-318$

Webster P J and Lukas R 1992 TOGA COARE: The Coupled Ocean-Atmosphere Response Experiment; Bull. Amer. Meteor. Soc. 73 1377-1416

William E R and Reno N 1993 An analysis of the conditional instability of the tropical atmosphere; Mon. Weather Rev. $12121-35$

Yano J E and Emmanuel K A 1991 An improved WISHE model of the equatorial atmosphere and its coupling with the stratosphere; J. Atmos. Sci. 48 377-389 